Federal Reserve Bank of Minneapolis

Research Department Staff Report 502

August 2014

\title{
Term Structures of Inflation Expectations and Real Interest Rates: The Effects of Unconventional Monetary Policy*
}

\author{
S. Borağan Aruoba \\ University of Maryland \\ and Federal Reserve Bank of Minneapolis
}

\begin{abstract}
Inflation expectations have recently received increased interest because of the uncertainty created by the Federal Reserve's unprecedented reaction to the Great Recession. The effect of this reaction on the real economy is also an important topic. In this paper I use various surveys to produce a term structure of inflation expectations - inflation expectations at any horizon from 3 to 120 months and an associated term structure of real interest rates. Inflation expectations extracted from this model track actual (ex-post) realizations of inflation quite well, and in terms of forecast accuracy they are at par with or superior to some popular alternatives obtained from financial variables. Looking at the period 2008-2013, I conclude that the unconventional policies of the Federal Reserve kept long-run inflation expectations anchored and provided a large level of monetary stimulus to the economy.
\end{abstract}

Keywords: Inflation expectations; Real interest rate; Unconventional policies JEL Classification: E31, E43, E58, C22

\footnotetext{
*The author is grateful to Tom Stark for extensive discussions about the Survey of Professional Forecasters, and to Frank Diebold, Frank Schorfheide, and Jonathan Wright for helpful comments. The views expressed herein are those of the author and not necessarily those of the Federal Reserve Bank of Minneapolis or the Federal Reserve System.
} 


\section{Introduction}

After almost two decades of being well anchored (and low), inflation expectations in the United States have recently received increased interest because of the uncertainty created by the Federal Reserve's unprecedented reaction to the Great Recession. ${ }^{1}$ Moreover, given that nominal interest rates are near zero, management of inflation expectations is a key component of the policies of the Federal Reserve. Thus, it seems more important than ever to track inflation expectations. Another important development since the Great Recession is the temporary end of conventional monetary policy, in which the Federal Reserve targets shortterm interest rates, due to the federal funds rate reaching the zero lower bound (ZLB). Much of the aforementioned reaction to the Great Recession was in the form of unconventional monetary policy, in which the Federal Reserve purchased various assets. Also of interest, then, is analyzing the effect of these policies on the term structure of real interest rates, which is a key part of the transmission mechanism of monetary policy.

In this paper I combine inflation expectations at various horizons from several surveys, to obtain a term structure of inflation expectations. Further combining this term structure of inflation expectations with the term structure of nominal interest rates, I obtain a term structure of real interest rates. In particular, I use inflation expectations from the Survey of Professional Forecasters (SPF), the Blue Chip Survey, and the Reuters/University of

\footnotetext{
${ }^{1}$ Many economists, especially in the popular press, have expressed wildly different views about the impact of the expansion of the Federal Reserve's balance sheet on inflation. For example, in an open letter to the Federal Reserve Chairman Ben Bernanke, 23 economists warned about the dangers of this expansion (see "Open Letter to Ben Bernanke," Real Time Economics (blog), Wall Street Journal, November 15, 2010, http://blogs.wsj.com/economics/2010/11/15/openletter-to-ben-bernanke/). A number of other economists, argued that this expansion is not a problem (see, e.g., Paul Krugman, "The Big Inflation Scare," New York Times, May 28, 2009, http://www.nytimes.com/2009/05/29/opinion/29krugman.html?ref=paulkrugman). This divide is also apparent within the Federal Open Market Committee. For a doveish view, see various 2010 speeches by president and CEO Charles Evans (Federal Reserve Bank of Chicago, http://www.chicagofed.org/webpages/publications/speeches/2010/index.cfm), which predict that inflation lower than $1.5 \%$ in three years' time is a distinct possibility. For a hawkish view, see various 2010 speeches by president and CEO Charles Plosser (Federal Reserve Bank of Philadelphia, http://www.philadelphiafed.org/publications/speeches/plosser/), which call for the winding down of special Fed programs to prevent an increase in inflation in the medium term.
} 
Michigan Survey of Consumers. I use the structure of the Nelson-Siegel model of the yield curve, which summarizes the yield curve with three factors (level, slope and curvature), and adapt it to the context of inflation expectations. Although no explicit restriction is imposed on how inflation expectations at different horizons are linked, the Nelson-Siegel model implicitly imposes a certain degree of smoothness. The end result is a monthly inflation expectations curve - inflation expectations at any horizon from 3 to 120 months - and, once combined with a nominal yield curve, an associated real yield curve from 1992 to the present. I compare the forecasts that come out of these inflation expectations curves with various alternatives, including those obtained from financial markets. Finally, I focus on the period 2008-2013 and use these inflation expectations and real yield curves to study the effects of various Federal Reserve actions during and following the financial crisis of 2008, including the initial quantitative easing (QE1), QE2, Operation Twist, and the announcement of an explicit inflation target. The results in this paper, and the technology that produces them, will be useful to policy makers and other observers in describing how inflation expectations and real interest rates evolve and respond to policy, both over time and across horizons. The methodology will also be useful to market participants who want to price securities with returns linked to inflation expectations of an arbitrary horizon.

In this paper I combine a number of survey-based inflation expectations in a reduced-form predictive model, the Nelson-Siegel model, as opposed to using a structural finance or macrofinance model that uses financial measures related to inflation expectations to back out the market's inflation expectations. I choose the specific path in this paper for at least three reasons. First, survey-based inflation expectations are known to be superior to those that come from models with financial variables. ${ }^{2}$ As such, combining surveys, all of which have some forecasting error, would in principle improve forecasting performance. Second, because of their nature, available surveys cover the inflation expectations curve very sparsely - at

\footnotetext{
${ }^{2}$ See, for example, Ang, Bekaert, and Wei (2007) and Faust and Wright (2013). The latter is an excellent survey of forecasting inflation in general.
} 
any point in time, a survey fills only a handful of points on this curve, and often these points are at nonstandard horizons. Combining these surveys to obtain a smooth curve that shows inflation expectations at any arbitrary horizon seems to be a useful exercise. The NelsonSiegel yield curve model is a parsimonious way of obtaining such a smooth curve. Third, the quality of the output of finance or macro-finance models depends crucially on how well the model captures the key links between asset prices and inflation expectations. Thus, any misspecification or structural breaks in the data would lead to an incorrect assessment of inflation expectations. One way to view the exercise in this paper, then, is as a test of the models that use financial variables.

Turning to the results, I show that the model can accurately summarize the information in surveys with small measurement errors, except for the Reuters/University of Michigan Survey, which differ significantly from other surveys. Long-run expectations, which are given by the level factor in the model, have a downward trend in the early 1990s and settle down to around $2.4 \%$ starting in 1998 . There are also significant changes in the slope of the inflation expectations curve during this period. I find that inflation expectations for the model track actual (ex-post) realizations of inflation quite well, indicating that combining various measures of expectations is a useful approach. More specifically, with a few minor exceptions, the forecasts from the model outperform alternatives, including those obtained using financial variables, and in some cases the difference in forecast accuracy is statistically significant. ${ }^{3}$ Finally, turning to the financial crisis of 2008 and the Federal Reserve's subsequent response, there is only a minor decline of around 14 basis points in 10-year inflation expectations after 2008. Moreover, much of this decline seems to come from lower inflation expectations in the short to medium run (up to two years), because the 3-year-to-10-year forecast does not show a discernible difference before and after 2008. Thus, to a good approximation, the level

\footnotetext{
${ }^{3}$ It is important to point out that all my model is designed to do is combine survey forecasts. If these survey forecasts were biased, for example, it would not be surprising to find that the output of my model does not line up well with realized inflation. Thus, these positive results show the joint success of the model that I employ, as well as the survey inputs that go into the model.
} 
of the inflation expectations curve remains unchanged. In other words, long-run inflation expectations remain anchored after the crisis and in response to (or despite) various Federal Reserve policies. Other parts of the inflation expectations curve and the entire real yield curve show significant declines after 2008. I find that inflation expectations for short to medium horizons recover after QE1 and QE2, but that these policies still lead to substantial declines in real interest rates, with the short-term real interest rate reaching $-2 \%$ by the end of 2012. Operation Twist, although not changing inflation expectations, reduces long-term real interest rates to a low of $-0.8 \%$ in the summer of 2012 . As a result, the whole real yield curve is below zero starting in September 2011, an unprecedented event in the sample I cover. In short, I conclude that these unconventional policies of the Federal Reserve, combined with the zero short-term policy rate, kept long-run inflation expectations anchored and provided a large level of monetary stimulus to the economy.

This paper is related to a number of recent studies, all but two of which use structural relationships to link asset prices with inflation expectations. Chernov and Mueller (2012) employ a no-arbitrage macro-finance model with two observed macro factors (output and inflation) and three latent factors. They estimate their model using nominal yields, inflation, output growth, and inflation forecasts from various surveys as well as Treasury Inflation-Protected Securities (TIPS) starting in 2003. Inflation expectations also have a factor structure, but unlike the model I use, the factors in their model are related to the yield curve and macroeconomic fundamentals, except for one factor that the authors loosely label as the "survey factor", the only one that affects the level of inflation expectations.

D'Amico, Kim, and Wei (2010) use a similar multifactor no-arbitrage term structure model estimated with nominal and TIPS yields, inflation, and survey forecasts of interest rates. Their explicit goal is to remove the liquidity premium that existed in the TIPS market for much of its existence in order to obtain a clean break-even inflation rate that may be useful for identifying real yields, inflation expectations, and the inflation risk premium. 
Their results clearly show the problem of using raw TIPS data due to the often large and time-varying liquidity premium. Haubrich, Pennacchi, and Ritchken (2012) use a model that has one factor for the short-term real interest rate, another for expected inflation rate, another factor that models the changing level to which inflation is expected to revert, and four volatility factors. They estimate their model using data that include nominal yields, survey forecasts, and inflation swap rates. I compare the forecasts produced by the latter two papers with the forecast generated by my model. ${ }^{4}$ I consider these two forecasts as cleaned versions of the TIPS data (for D'Amico, Kim, and Wei, 2010) and swap rates (for Haubrich, Pennacchi, and Ritchken, 2012). My results show that although these cleaned versions outperform their raw counterparts, the forecast from my model still outperforms them. Much of the improvement in forecast accuracy from my model comes from the lack of volatility in the model forecast relative to that of the financial variable-based forecasts.

Ajello, Benzoni, and Chyruk (2012) take a somewhat different route. They use the nominal yields at a given point in time to forecast inflation at various horizons using a dynamic term structure model that has inflation as one of the factors. The important distinction of this paper relative to some others is that they separately model the changes in core, energy, and food prices since, as they show, each of these components have different dynamics. They forecast inflation based on nominal yields and other data, and show that the model forecast is at par with survey forecasts in terms of accuracy. Mertens (2011) sets out to extract trend inflation (long-run inflation) from financial variables and surveys. His data consists of long-horizon surveys, realized inflation measures, and long-term nominal yields. He uses a reduced-form factor model with a level and uncertainty factor that captures stochastic volatility in the trend process. My results regarding long-run inflation expectations are similar to his.

\footnotetext{
${ }^{4}$ The forecasts of D'Amico, Kim, and Wei (2010) are graciously provided by the Federal Reserve Board. The forecasts of Haubrich, Pennacchi, and Ritchken (2012) are available from the website of the Federal Reserve Bank of Cleveland, http://www.clevelandfed.org.
} 
Finally, perhaps the two papers closest to this one are Christensen, Lopez and Rudebusch (2010) and Gürkaynak, Sack, and Wright (2010). The former estimates a variant of the arbitrage-free Nelson-Siegel model using both nominal and real (TIPS) yields. As a result of their estimation, they can calculate the model-implied inflation expectations and the risk premium. Although the model they use and the overall reduced-form flavor are similar to my paper, I model inflation expectations directly and do not use any financial data. The latter paper uses nominal yield data to estimate a nominal term structure and TIPS data to estimate a real term structure, both by using a generalization of the Nelson-Siegel structure (the so-called Nelson-Siegel-Svensson form). They then define inflation compensation as the difference between these two term structures. By comparing inflation compensation with survey expectations, they show that it is not a good measure of inflation expectations because it is affected by the liquidity premium and an inflation risk premium. I take the opposite route in this paper, in that I construct a term structure of inflation expectations solely from surveys and compare them with measures from financial variables.

The paper is organized as follows. In Section 2.1, I describe the model used in the estimation, and in Section 2.2 I provide details about the surveys used as inputs in the estimation. Section 2.3 provides a summary of the full state-space model and its estimation. Section 3.1 discusses the estimation results, and Section 3.2 compares the resulting inflation expectations curve to some alternatives. Section 4 focuses on the period 2008-2013, and discusses how inflation expectations and real yield curves evolve in this period, focusing on the effects of some key Federal Reserve policies. Section 5 provides some concluding remarks. An online appendix contains additional results. 


\section{Model}

\subsection{Term Structure of Inflation Expectations}

The Nelson and Siegel (1987) yield curve model (henceforth the NS model) is frequently used both in academic studies and by practitioners. As restated in Diebold and Li (2006), the model links the yield of a bond with $\tau$ months to maturity, $y_{t}(\tau)$, to three latent factors, labeled level, slope, and curvature, according to

$$
y_{t}(\tau)=L_{t}-\left(\frac{1-e^{-\lambda \tau}}{\lambda \tau}\right) S_{t}+\left(\frac{1-e^{-\lambda \tau}}{\lambda \tau}-e^{-\lambda \tau}\right) C_{t}+\varepsilon_{t}
$$

where $L_{t}, S_{t}$ and $C_{t}$ are the three factors, $\lambda$ is a parameter and $\varepsilon_{t}$ is a measurement error. ${ }^{5}$ The factors evolve according to a persistent process, inducing persistence on the yields across time. Numerous studies show that the NS model is a very good representation of the yield curve both in the cross section and dynamically. ${ }^{6}$ This model is very popular for at least three reasons. First, the factor loadings for all maturities are characterized by only one parameter, $\lambda$. This makes scaling up by adding more maturities relatively costless. Second, the specification is very flexible, capturing many of the possible shapes the yield curve can take: (1) can lead to an upward or downward sloping yield curve, which has at most one peak, whose location depends on the value of $\lambda .^{7}$ Third, it imposes a degree of smoothness on the yield curve that is reasonable; wild swings in the yield curve at a point in time are not common.

Many of the properties of the yield curve, such as smoothness and persistence, are also shared by the term structure of inflation expectations. Thus, modelin the latter by the NS

\footnotetext{
${ }^{5}$ The original NS model starts with the assumption that the forward rate curve is a variant of a Laguerre polynomial, which results in the function in (1) when converted to yields. As such it has no economic foundation, unlike some of the papers cited in the introduction that contain asset-pricing models.

${ }^{6}$ For a extensive survey, see Diebold and Rudebusch (2013).

${ }^{7}$ The slope factor in Diebold and $\mathrm{Li}$ (2006) is defined as $-S_{t}$. The three factors are labeled as such because, as Diebold and Li (2006) demonstrate, $L_{t}=y_{t}(\infty), S_{t}=y_{t}(\infty)-y_{t}(0)$ (with the definition adopted in this paper), and the loading on $C_{t}$ starts at zero and decays to zero affecting the middle of the yield curve where the maximum loading is determined by the value of $\lambda$.
} 
model is not too much of a stretch. Defining $\pi_{t}(\tau)$ as the $\tau$-month inflation expectations from the end of month $t$ to the end of month $t+\tau$, I assume that it follows the process

$$
\pi_{t}(\tau)=L_{t}-\left(\frac{1-e^{-\lambda \tau}}{\lambda \tau}\right) S_{t}+\left(\frac{1-e^{-\lambda \tau}}{\lambda \tau}-e^{-\lambda \tau}\right) C_{t}+\varepsilon_{t}
$$

According to this specification, long-term inflation expectations will be captured by $L_{t}$, higher long-term inflation expectations relative to short-term expectations will be captured by $S_{t}$, and $C_{t}$ will capture higher medium-term expectations relative to short- and long-term expectations.

I set up a state space model, following the approach in Diebold, Rudebusch and Aruoba (2006), where (2) constitutes a generic measurement equation. To complete the state-space representation, I assume that the three latent factors follow the independent $\operatorname{AR}(3)$ processes $^{8}$

$$
\begin{aligned}
& L_{t}=\mu_{L}+\rho_{11}\left(L_{t-1}-\mu_{L}\right)+\rho_{12}\left(L_{t-2}-\mu_{L}\right)+\rho_{13}\left(L_{t-3}-\mu_{L}\right)+\eta_{t}^{L} \\
& S_{t}=\mu_{S}+\rho_{21}\left(S_{t-1}-\mu_{S}\right)+\rho_{22}\left(S_{t-2}-\mu_{S}\right)+\rho_{23}\left(S_{t-3}-\mu_{S}\right)+\eta_{t}^{S} \\
& C_{t}=\mu_{C}+\rho_{31}\left(C_{t-1}-\mu_{C}\right)+\rho_{32}\left(C_{t-2}-\mu_{C}\right)+\rho_{33}\left(C_{t-3}-\mu_{C}\right)+\eta_{t}^{C},
\end{aligned}
$$

where $\eta_{t}^{i} \sim N\left(0, \sigma_{i}^{2}\right)$ and $\operatorname{cov}\left(\eta_{t}^{i}, \eta_{t}^{j}\right)=0$ where $i, j=L, S$, and $C$ and $i \neq j$.

Once the model is cast in state space, combining (2) and (3), estimation and inference are standard. As will be clear below, one particular property of the setup in this paper is the existence of many missing observations. As shown in the literature, the Kalman filter and the state-space methods associated with it are well suited to handle them. ${ }^{9}$

Next, I turn to developing some results that will facilitate mapping various observables into measurement equations. First, I define inflation between two arbitrary dates. The

\footnotetext{
${ }^{8}$ Initially, I consider three alternatives: independent AR(3)'s for each factor, a VAR(1), and a VAR(3) containing all three factors. I found that the former is preferred by the Schwartz information criterion, especially considering that it has 18 less parameters relative to a $\operatorname{VAR}(3)$. It is also useful to point out that the extracted factors in the three versions are essentially identical.

${ }^{9}$ See, for example, Diebold, Rudebusch, and Aruoba (2006) for the details of estimating the NS model, Aruoba, Diebold, and Scotti (2009) for a specific example with a state-space model with many missing observations, and Durbin and Koopman (2001) for a textbook treatment of both.
} 
Bureau of Labor Statistics, the statistical agency that measures the consumer price index (CPI) in the United States, uses the simple growth rate formula to compute inflation. Using this formula in this context, however, leads to a nonlinear state space, which is considerably more difficult to handle. Thus, I define inflation using continuous compounding instead. ${ }^{10}$ More specifically, let $P_{t}$ be the CPI price level at the end of month $t$. I define

$$
\pi_{t \rightarrow s} \equiv 100 \times \frac{12}{s-t}\left[\log \left(P_{s}\right)-\log \left(P_{t}\right)\right]
$$

as the annualized inflation rate between the end of month $t$ and the end of month $s$. In terms of the notation in $(2), \pi_{t}(\tau) \equiv \pi_{t \rightarrow t+\tau}$ for $\tau>0$. This notation is quite flexible. For example, $\pi_{t \rightarrow t+12}$ denotes the expected inflation between the end of the month in $t$ to the end of the month in month $t+12$, or a conventional one-year-ahead forecast, whereas $\pi_{t+3 \rightarrow t+6}$ is the expected quarterly inflation starting from the end of month $t+3$. The former can be immediately written as $\pi_{t}(12)$, but to convert the latter to this notation, the following result is useful.

Proposition 1 Consider $\pi_{t \rightarrow t+s}, \pi_{t \rightarrow t+r}$, and $\pi_{t+r \rightarrow t+s}$ where $s>r>0$. These are related by

$$
\pi_{t+r \rightarrow t+s}=\frac{s}{s-r} \pi_{t \rightarrow t+s}-\frac{r}{s-r} \pi_{t \rightarrow t+r} .
$$

Proof. See the online appendix.

As an intuitive example of this result, the formula yields $\pi_{t \rightarrow t+6}=0.5 \times\left(\pi_{t \rightarrow t+3}+\pi_{t+3 \rightarrow t+6}\right)$, which shows that the six-month inflation rate is simply the average of the two three-month inflation rates, one from today to three months from now and the other between three and six months from now.

Finally, to map any inflation measure $\pi_{t+\tau_{1} \rightarrow t+\tau_{2}}$ in to the factor model in (2), I derive the following result.

\footnotetext{
${ }^{10}$ In practice, this turns out to be a very minor issue. See footnote 27.
} 
Proposition 2 An inflation measure $\pi_{t+\tau_{1} \rightarrow t+\tau_{2}}$ where $\tau_{2}>\tau_{1} \geq 0$ can be written as

$$
\pi_{t+\tau_{1} \rightarrow t+\tau_{2}}=L_{t}+\frac{e^{-\lambda \tau_{1}}-e^{-\lambda \tau_{2}}}{\lambda\left(\tau_{2}-\tau_{1}\right)}\left(C_{t}-S_{t}\right)+\left(\frac{\tau_{1} e^{-\lambda \tau_{1}}-\tau_{2} e^{-\lambda \tau_{2}}}{\tau_{2}-\tau_{1}}\right) C_{t}
$$

Proof. See the online appendix.

As should be clear from inspecting (6), using continuous compounding, I preserve the linearity of the state-space system, which would not be possible with a simple growth formula.

\subsection{Measurement Equations}

With the result of Proposition 2 in hand, all that remains to be done is to map observed measures of inflation expectations into the framework described so far. Letting $x_{t}^{i}$ be a generic observable, this amounts to writing

$$
x_{t}^{i}=\left(\begin{array}{ccc}
f_{L}^{i} & f_{S}^{i} & f_{C}^{i}
\end{array}\right)\left(\begin{array}{c}
L_{t} \\
S_{t} \\
C_{t}
\end{array}\right)+\varepsilon_{t}^{i}
$$

where $\left\{f_{L}^{i}, f_{S}^{i}, f_{C}^{i}\right\}$ are the loadings on the three factors and $\varepsilon_{t}^{i} \sim N\left(0, \sigma_{i}^{2}\right)$ is an idiosyncratic error term, which accounts for deviations from the factor model. Survey-specific details are provided in the online appendix.

\subsection{State-Space System and Methodology}

The preceding section and the details in the appendix showed the measurement equations of the observable variables I use in my analysis - all in all, 37 variables. It is important to note that the matrix of observables is considerably sparse due to the quarterly frequency of the SPF and the fact that I used multiple observable variables for a given forecast. Combining all the measurement equations and the transition equation for the three factors, I obtain a state-space system

$$
\begin{aligned}
\mathbf{x}_{t} & =\mathbf{Z} \boldsymbol{\alpha}_{t}+\varepsilon_{t} \\
\left(\boldsymbol{\alpha}_{t}-\boldsymbol{\mu}\right) & =\mathbf{T}\left(\boldsymbol{\alpha}_{t-1}-\boldsymbol{\mu}\right)+\boldsymbol{\eta}_{t}
\end{aligned}
$$


with

$$
\varepsilon_{t} \sim N(0, \mathbf{H}) \text { and } \boldsymbol{\eta}_{t} \sim N(0, \mathbf{Q})
$$

where the notation follows the standard notation in Durbin and Koopman (2001). The vector $\mathbf{x}_{t}$ is a $37 \times 1$ vector containing all observed variables in period $t$, and $\boldsymbol{\alpha}_{t}$ is a $9 \times 1$ vector that collects the three inflation expectation factors and their two lags in period $t$ :

$$
\boldsymbol{\alpha}_{t}=\left[\begin{array}{lllllllll}
L_{t} & S_{t} & C_{t} & L_{t-1} & S_{t-1} & C_{t-1} & L_{t-2} & S_{t-2} & C_{t-2}
\end{array}\right]^{\prime} .
$$

The $\varepsilon_{t}$ are the measurement errors, and thus $\mathbf{H}$ is a diagonal matrix with

$$
\mathbf{H}=\operatorname{diag}\left(\sigma_{1}^{2}, \sigma_{2}^{2}, \ldots, \sigma_{37}^{2}\right)
$$

The measurement matrix $\mathbf{Z}$ collects the factor loadings described in the online appendix and is given by

$$
\mathbf{Z}=\left[\begin{array}{ccccccccc}
f_{L}^{1} & f_{S}^{1} & f_{C}^{1} & 0 & 0 & 0 & 0 & 0 & 0 \\
f_{L}^{2} & f_{S}^{2} & f_{C}^{2} & 0 & 0 & 0 & 0 & 0 & 0 \\
\vdots & \vdots & \vdots & \vdots & \vdots & \vdots & \vdots & \vdots & \vdots \\
f_{L}^{37} & f_{S}^{37} & f_{C}^{37} & 0 & 0 & 0 & 0 & 0 & 0
\end{array}\right]
$$

The transition matrix $\mathbf{T}$ takes the form

$$
\mathbf{T}=\left[\begin{array}{ccccccccc}
\rho_{11} & 0 & 0 & \rho_{12} & 0 & 0 & \rho_{13} & 0 & 0 \\
0 & \rho_{21} & 0 & 0 & \rho_{22} & 0 & 0 & \rho_{23} & 0 \\
0 & 0 & \rho_{31} & 0 & 0 & \rho_{32} & 0 & 0 & \rho_{33} \\
1 & 0 & 0 & 0 & 0 & 0 & 0 & 0 & 0 \\
0 & 1 & 0 & 0 & 0 & 0 & 0 & 0 & 0 \\
0 & 0 & 1 & 0 & 0 & 0 & 0 & 0 & 0 \\
0 & 0 & 0 & 1 & 0 & 0 & 0 & 0 & 0 \\
0 & 0 & 0 & 0 & 1 & 0 & 0 & 0 & 0 \\
0 & 0 & 0 & 0 & 0 & 1 & 0 & 0 & 0
\end{array}\right]
$$

and the constant $\boldsymbol{\mu}$ is given by

$$
\boldsymbol{\mu}=\left[\begin{array}{lllllllll}
\mu_{L} & \mu_{S} & \mu_{C} & 0 & 0 & 0 & 0 & 0 & 0
\end{array}\right]^{\prime} .
$$


Finally, $\mathbf{Q}$ is a diagonal matrix with

$$
\mathbf{Q}=\operatorname{diag}\left(\eta_{t}^{L}, \eta_{t}^{S}, \eta_{t}^{C}, 0,0,0,0,0,0\right)
$$

The model is estimated using maximum likelihood via the prediction-error decomposition and the Kalman filter. A total of 53 parameters are estimated, where all but 16 of these parameters are measurement error variances. The smoothed estimates of the level, slope, and curvature factors are obtained using the Kalman smoother.

\subsection{Term Structure of Real Interest Rates}

The Fisher equation links the nominal interest rate to the real interest rate and expected inflation. Generalizing to a generic maturity, I can write it as

$$
y_{t}(\tau)=r_{t}(\tau)+\pi_{t}(\tau),
$$

where $y_{t}(\tau)$ and $r_{t}(\tau)$ are the nominal and real continuously compounded interest rates or yields for a bond that is purchased in period $t$ and matures in period $t+\tau$. It is important to note that by decomposing the nominal rate as above, I implicitly include the inflation risk premium in $r_{t}(\tau)$. In Section 4.2 I discuss how this approach may affect my findings.

Since I already obtained $\pi_{t}(\tau)$ above, all I need to do to obtain the term structure of real interest rates is to obtain the term structure of nominal interest rates. To that end, I could simply use (1) along with data on yields. Instead, I use the estimated yield curve as computed by the Board of Governors of the Federal Reserve System, following Gürkaynak, Sack, and Wright (2007). This yield curve is estimated using a generalized specification of the Nelson-Siegel model, the so-called Nelson-Siegel-Svensson specification, which adds one more factor to the original Nelson-Siegel model. More specifically, the measurement equation 
becomes

$$
\begin{aligned}
y_{t}(\tau)= & L_{t}^{y}-\left(\frac{1-e^{-\lambda_{1, t} \tau}}{\lambda_{1, t} \tau}\right) S_{t}^{y}+\left(\frac{1-e^{-\lambda_{1, t} \tau}}{\lambda_{1, t} \tau}-e^{-\lambda_{1, t} \tau}\right) C_{1, t}^{y} \\
& +\left(\frac{1-e^{-\lambda_{2, t} \tau}}{\lambda_{2, t} \tau}-e^{-\lambda_{2, t} \tau}\right) C_{2, t}^{y},
\end{aligned}
$$

which simplifies to (1) when $\lambda_{2, t}=0$. Unlike the dynamic approach I take in this paper, or the approaches in Diebold and Li (2005) or Diebold, Rudebusch, and Aruoba (2006), Gürkaynak, Sack and Wright (2007) treat $L_{t}^{y}, S_{t}^{y}, C_{1, t}^{y}, C_{2, t}^{y}, \lambda_{1, t}, \lambda_{2, t}$ as parameters and estimate (17) every period. These parameters are reported for every day since June 1961, which enables me to compute $y_{t}(\tau)$ for any arbitrary maturity $\tau$. In turn, I compute the continuously compounded real interest curve, $r_{t}(\tau)$, using (16).

\section{Inflation Expectations Curve}

The state-space model presented in the previous section is estimated on a sample that covers the period from January 1992 through July 2013. The starting point of the sample is dictated by the availability of the 10-year forecast from the SPF. All raw data are converted to annualized percentage rates. ${ }^{11}$

\subsection{Estimation Results}

Table 1 presents the estimated parameter values. Panel (a) shows the estimated transition equation parameters. The level factor is a near unit root (but covariance stationary), with the smallest root of the characteristic polynomial slightly above unity. The slope and curvature factors are also covariance stationary, and all three factors have both imaginary and real roots. The long-run average of the level factor is just above $3 \%$. The level factor captures the very long-run inflation expectations, and the estimated value reflects the higher inflation expectations in the early 1990s due to the high levels of inflation in the 1980s. The average

\footnotetext{
${ }^{11}$ When I carried out the estimation using a longer sample, the results for the post-1992 period were virtually identical to the results presented here.
} 
slope of the inflation expectations curve, which is defined as the difference between long-term and short-term expectations, is mildly positive at 36 basis points. The curvature factor has roughly a zero mean. The variances of the transition equation innovations are very small.

Panel (b) of Table 1 shows that $\lambda$ is estimated as 0.16 , which means that the loading on the curvature factor is maximized at just over 11 months. Two broad conclusions emerge from looking at the measurement error variances. First, as the forecast horizon of the variable increases, the measurement error variances become smaller, indicating a better fit of the model. Second, the Michigan Survey variables display measurement error variances that are about two orders of magnitude bigger than those for other sources at similar forecast horizons. This means that there is a significant mismatch between Michigan Survey variables and other forecasts, which is apparent when one plots, for example, the one-year Michigan Survey and the SPF forecasts. ${ }^{12}$

Given these estimated parameters, I obtain estimates of the three factors using the Kalman smoother, which are presented in Figure $1 .{ }^{13}$ As expected, the level factor (longrun inflation expectations) has a downward trend that flattens out by the early 2000s, after which point it stays around $2.4 \%$. The slope factor is positive for much of the sample, falling below zero just before the 2001 recession, in 2006, and during the Great Recession, prior to the financial crisis of 2008. As I show in detail in Section 4.1, during the financial crisis the inflation expectations curve sharply steepens, with much of the movement coming from the short end. This is also visible in this figure as the sharp increase in the slope near September 2008. The curvature factor has smaller fluctuations, and except for 2003 and the time following the financial crisis, where it was negative, it remains near zero for extended periods. In fact, it seems that the curvature factor is negative in the early parts of recoveries after

\footnotetext{
${ }^{12}$ This is in line with the findings of Ang, Bekaert, and Wei (2007), who conclude that the professionals uniformly beat the consumers in forecasting inflation.

${ }^{13}$ In all figures the two NBER recessions in the sample are shown with gray shading, and September 2008 is shown with a vertical line. The latter is arguably the height of the financial crisis, and significant changes occur in both the inflation forecasts and the financial variables introduced below. Also, where relevant, I use red dashed lines to denote pointwise $95 \%$ confidence bands.
} 
recessions, indicating that the inflation expectations curve is U-shaped.

The main output from the estimation that is of interest is the inflation expectations curve itself. I focus on the post-2008 period in Section 4.1. In Figure 2, I show the time series of some selected inflation expectations: those at a 6-month and at 1-, 5-, and 10-year horizons. In addition to the decline since the 1990s in all horizons, it is also apparent that as the forecast horizon increases, the forecasts become smoother.

\subsection{Comparison of Forecasts}

In this section I compare the forecasts from the model with some alternatives. First, I present results that compare the model's forecasts with some of the survey inputs that enter the model. This approach will demonstrate the benefit of combining multiple forecasts, which goes beyond the standard result where combining multiple forecasts improves forecast accuracy. The inputs of the model provide information about various parts of the inflation expectations curve, with very few overlaps. In that sense, combining them will not be the same as combining forecasts of the same object; rather it will be combining the information in nearby forecast horizons. Second, I compare them with measures obtained from financial variables. These variables are followed widely and considered by many as gauges of the market's inflation expectations.

I present two sets of results. Figures 3, 4, and 5, each with two panels, show plots of the forecasts from the model, the actual inflation that was realized, and a number of alternative measures. Table 2 presents formal forecast comparison test results using realized inflation. The latter is a useful exercise, since the ultimate goal of the technology developed in this paper is to construct good forecasts of inflation at various horizons. ${ }^{14}$ To remind the readers, in what follows an $N$-month forecast refers to the inflation expectations between the present

\footnotetext{
${ }^{14}$ One may take the point of view that if the underlying inflation forecasts are not good in a forecast accuracy sense, then the resulting combination would not be good either, and this is not necessarily a problem. I want to demonstrate, however, that the resulting inflation forecasts indeed have good forecasting properties.
} 
and $N$ months from now. The first panel of Table 2 shows that the model forecast is superior to a random walk (no-change) forecast and is statistically significant for all but the 10-year forecast.

\subsubsection{Comparison with Inputs}

The top panel of Figure 3 shows the one-year forecast and various alternative measures. As inputs, it shows the implied Blue Chip forecast and a variable from the SPF. ${ }^{15}$ As expected, the model forecast closely follows the inputs and is much less volatile than actual inflation. ${ }^{16}$ The mean model forecast is identical to that of actual inflation, a property it shares with the Blue Chip forecast. The top panel of Figure 4 shows the 10-year model forecast and the approximate forecast from the SPF, but since there is only ten common observations, it is difficult to reach any conclusions. ${ }^{17}$ The top panel of Figure 5 shows the ten-year model forecast and the approximate forecast from the SPF. In the earlier part of the sample, roughly until 1998, the SPF forecast and the model forecast are significantly above actual inflation. As is well known, this result is due to the overhang from the high-inflation period of the 1980s. After 1998 long-run inflation expectations start to get anchored near the Federal Reserve's implicit target of $2 \% .{ }^{18}$ The model forecast closely follows the approximate SPF forecast, but it also uses the long-term Blue Chip forecasts (not shown) that have information about nearby horizons.

\footnotetext{
${ }^{15}$ The implied Blue Chip forecast is simply the average of the $t \rightarrow t+3, t+3 \rightarrow t+6, t+6 \rightarrow t+9$, and $t+9 \rightarrow t+12$ forecasts and is available quarterly. For the SPF I use the Annual "B" forecast for the fourth quarter of every year which corresponds to $t+1 \rightarrow t+13$ forecast and is available annually.

${ }^{16}$ The actual inflation measure is the appropriate difference of the natural logarithm of CPI, as extracted from FRED in December 2013, with the FRED code CPIAUCSL.

${ }^{17}$ The forecast from the SPF is approximate since it combines three of the 5 -year forecasts which are from period $t$ to $t+52, t+55$, and $t+58$. A similar comment applies to the approximate 10-year forecast in Figure 5.

${ }^{18}$ The Federal Reserve emphasizes the inflation rate based on personal consumption expenditures (PCE) and since January 2012 it has an explicit target of $2 \%$ based on this measure. Although PCE inflation uses the same underlying source data, it uses weights different from the CPI inflation. Their levels are also somewhat different, with CPI inflation being slightly larger than PCE inflation on average. The analysis in this paper is done using CPI inflation, since historical forecasts for PCE are not available at multiple frequencies. See also footnote 23 .
} 
The first panel of Table 2 shows the forecast comparison results versus some of the inputs. The first column reports the root-mean-squared error (RMSE) of the model forecast, the second column reports the RMSE of the alternative measure considered and the third column shows the number of observations available for each comparison. Boldface in a given column indicate the rejection of the null of equal forecast accuracy in favor of the forecast in that column using the Diebold and Mariano (1995) test with the squared-error loss function. The results show that the model forecast is a better forecast in terms of RMSE relative to the three inputs considered, though this is not statistically significant at the $5 \%$ significance level.

\subsubsection{Comparison with Measures Derived from Financial Variables}

It is well understood that many financial variables contain information about the market participants' inflation expectations. Perhaps the two financial instruments that have the most information are inflation swaps and Treasury Inflation-Protected Securities (TIPS). An inflation swap is an agreement in which one party makes periodic payments to another party, which are linked to inflation realized in the future, in exchange for a fixed payment up front. In a perfect world, one without risk premia, and one in which all assets are arbitrarily liquid, this fixed payment will be a good estimate of the two participants' inflation forecasts. TIPS, on the other hand, are bonds issued by the U.S. Treasury, with yields that are linked to future realized inflation rates. Again, in a perfect world, the difference between the yield on a TIPS at a certain maturity and the U.S. Treasury nominal yield at the same maturity, the so-called break-even rate (or inflation compensation), will be a good estimate for the inflation expectations of the market. ${ }^{19}$

As it turns out, we do not live in such a perfect world - one without risk premia and arbitrarily liquid asset markets. The liquidity of the TIPS market has changed significantly

\footnotetext{
${ }^{19}$ The TIPS rate is linked explicitly to seasonally adjusted CPI. Swap rates are linked to seasonally unadjusted CPI. Although there does not seem to be any discernible seasonality in swap rates, this certainly complicates models in which swap rates are used.
} 
since its inception, which makes it very difficult to use the break-even rate as a direct estimate of inflation expectations. Similar problems also plague the inflation swaps market. ${ }^{20}$ D'Amico, Kim, and Wei (2010) utilize a no-arbitrage asset pricing model to produce market inflation expectations using the TIPS break-even rate, as well as nominal U.S. Treasury yields. This measure is widely used as a clean version of the TIPS break-even rate. Haubrich, Pennacchi, and Ritchken (2012) follow an approach that is broadly similar, in that they consider an asset pricing model that has implications for nominal yields and swap rates, and the model is estimated using these observables, as well as some forecasts from the Blue Chip Economic Indicators and the SPF. ${ }^{21}$

The bottom panel of Figure 3 shows the one-year swap rate and the results from Haubrich, Pennacchi, and Ritchken (2012), labeled as "Cleveland Fed." Two things are very clear. The Cleveland Fed forecast and the swap rate, when it is available, are significantly more volatile than the model forecast. Also, the swap rate takes a significant dive near the financial crisis, falling to nearly $-4 \%$, while the $\mathrm{SPF}$ and model forecasts remain slightly above $1 \%$. It is quite clear that the raw swap rate suffers from the problems I list above. Although not as extreme as the swap rate, the Cleveland Fed forecast also displays similar behavior, falling below zero in early 2009.

Figure 4 shows the five-year swap rate, TIPS break-even rate, and the results from D'Amico, Kim, and Wei (2010), labeled "DKW Inflation Expectation." Also shown is the Cleveland Fed forecast, with TIPS-related variables in the top panel and the swap-raterelated variables in the bottom panel. The TIPS break-even rate clearly displays very differ-

\footnotetext{
${ }^{20}$ David Lucca and Ernst Schaumburg provide a good summary of these problems and some others that make TIPS and swap rates noisy indicators of inflation expectations. See David Lucca and Ernst Schaumburg, "What to Make of Market Measures of Inflation Expectations?" Liberty Street Economics (blog), Federal Reserve Bank of New York, August 15, 2011, http://libertystreeteconomics.newyorkfed.org/2011/08/whatto-make-of-market-measures-of-inflation-expectations.html.

${ }^{21}$ Both D'Amico, Kim, and Wei (2010) and Haubrich, Pennacchi, and Ritchken (2012) start their estimation prior to the introduction of TIPS and swaps, respectively, using nominal yields as the only financial asset. As such, their reported inflation expectations can be considered as cleaned TIPS and swaps only after 1999 for TIPS and 2004 for swaps.
} 
ent behavior before 2003 and again after the financial crisis in 2008 relative to both actual inflation and the model forecast. A similar conclusion also applies for the swap rate, which is available for a shorter sample. Both rates fall below zero during the financial crisis. Both DKW and the Cleveland Fed forecasts behave much better relative to the raw financial variables, although especially after 1998, when the long-run inflation expectations start to settle, they are more volatile relative to the model forecast. Figure 5 shows the same variables for the 10-year horizon, and by and large the same conclusions apply.

The rest of Table 2 shows forecast comparison results for the variables discussed in this section. The raw financial variables, shown in the third and fourth panels, produce substantially worse forecasts relative to the model forecast, with improvements in the RMSEs of the latter as large as $67 \%$ for the 10-year TIPS break-even rate. Looking deeper to the source of the large RMSE for this particular variable, it is twice as volatile as the model forecast and that the bias is $-0.3 \%$ versus $0.1 \%$ for the model forecast. The DKW and Cleveland Fed forecasts produce results that are much better, with RMSEs that are roughly half of the raw financial variables and near the values attained by the model forecast. The model forecast comes out significantly more accurate than the two-year Cleveland Fed forecast, with the model forecast producing better RMSEs in all other cases. The model forecast is significantly more accurate than the 5-year and 10-year DKW forecast, whereas for the 2-year forecast the DKW forecast produces a lower RMSE, although the difference in forecast accuracy is not statistically significant. ${ }^{22}$

I view the results of this section as making a strong case for the usefulness of the model forecast relative to a number of alternatives related to the financial markets. This strong case is also why I chose not to use any financial variables in the model developed in this

\footnotetext{
${ }^{22}$ For the DKW forecast, I restrict the results to the sample starting in 1999, when actual TIPS data are available. If I start the forecast comparison in 1992, the DKW forecast produces a lower RMSE with an insignificant difference in forecast accuracy. In the very early part of the sample, the model forecast significantly overshoots the longer-term forecasts due to the overhang I mentioned above. When I redo the comparison starting in 1994 instead of 1992, the model forecast has lower RMSE than the DKW forecast for all three horizons considered.
} 
paper. $^{23}$ The results in this section are also a confirmation and generalization of the results in Gürkaynak, Sack, and Wright (2010), who show that inflation compensation from TIPS has been far more volatile than survey expectations from the Blue Chip Survey and that the two have no consistent relationship.

\section{Unconventional Monetary Policy: 2008-2013}

The results so far show that the inflation expectations curve obtained from the model, to the extent that it can be compared with alternatives, seems to be a good measure. In this section I put it to use, along with the real yield curve obtained following the procedure discussed in Section 2.4, and analyze how they evolved between 2008 and 2013. This is a very important period on which to focus. As I discussed earlier, the Federal Reserve by and large had succeeded in anchoring long-run inflation expectations starting in 1998. Between 1999 and 2007, the 10-year forecast from the model fluctuates between $2.3 \%$ and 2.7\%, with an average of $2.5 \% .{ }^{24}$ Since conventional monetary policy, targeting the federal funds rate, which was arguably the main tool that the Fed used to keep inflation (and its expectations) under control in this period, ceased to be effective with the nominal interest rates hitting the zero lower bound in early 2009, it is important to see whether long-run inflation expectations become unhinged. Moreover, since the Federal Reserve started conducting various unconventional policies in response to and following the financial crisis, it is also interesting

\footnotetext{
${ }^{23}$ In an earlier version of the paper, I experimented with using some of these financial variables as inputs. However, since they disagreed with the SPF and other survey-based forecasts quite drastically, it was not possible to obtain a useful combination of all the forecasts. This approach is akin to trying to find the common factor of unrelated variables where the result would typically be one of the variables.

${ }^{24}$ It is important to note that although the Federal Reserve did not have a formal inflation target until 2012 , it was well understood that it would not allow inflation to go much above $2 \%$. It may be somewhat surprising that the average 10-year expectations in the model are $0.5 \%$ (more precisely, 46 basis points) larger, but one must keep in mind that the Fed does not target the inflation over a 10-year horizon, as fluctuations in the short run do cause its policy to react. In fact, in a press release from January 25, 2012, the Federal Open Market Committee identifies the annual change in the price index for personal consumption expenditures as its explicit target. When I compare the long-run averages of CPI-based and PCE-based annual inflation rates, the difference is 36 basis points. So, it seems that much of the difference arises from the difference between these two measures. The remaining could reflect the market's assessment of the possibility of events that make inflation rise at some time over the next 10 years.
} 
to analyze the impact of these policies on the inflation expectations curve. ${ }^{25}$ Finally, some, if not most of these unconventional policies were aimed at providing additional stimulus for the real side of the economy, and by looking at the real yield curve, we can investigate whether these policies they succeeded. ${ }^{26}$

I focus on five specific events in this period: the financial crisis, the initial quantitative easing (QE1), QE2, Operation Twist, and the Federal Reserve's explicit adoption of an inflation target. ${ }^{27}$ Although determining the start of the financial crisis is difficult, I use September 2008, which is when much of the major events happened. QE1, which consists of a number of large-scale asset purchase programs, started in December 2008 and concluded by August 2010, after having increased the balance sheet of the Fed by some $\$ 1.75$ trillion. QE2, which consisted of a plan to purchase $\$ 600$ billion of long-term Treasury securities, was put in place between November 2010 and June 2011. Operation Twist (formally known as the Maturity Extension Program) aimed at increasing the maturity of the Fed's assets and was in effect between September 2011 and December 2012. Finally, the Federal Reserve announced a formal inflation target of $2 \%$ on January 25, 2012. Below, I look at how the inflation expectations and real interest rate curves change around these dates. One small caveat to note: it is conceivable that some other events, in addition to and unrelated to the Fed programs, may have an impact on inflation expectations and real interest rates. However, it is difficult to argue that events other than actions by the Federal Reserve may have as large an impact on inflation expectations, especially during the period I consider. A

\footnotetext{
${ }^{25}$ Some (perhaps all) of this analysis can be conducted by looking at the survey forecasts I use in my model and at some financial variables. However, the previous section showed that based on historical forecasting performance, both sets of measures are expected to be inferior to the model forecast. Also, the survey variables for the long-horizon forecasts are only available quarterly, which severely restricts their use for this purpose.

${ }^{26}$ Here I have in mind a very general model where the real interest rate is one of the key determinants of current economic activity. A decline in the real interest rate stimulates private consumption demand by making consumption cheaper today as opposed to the future, and it also boosts investment by reducing the opportunity cost of funds used for investment.

${ }^{27}$ Inflation expectations and real interest rates at various key horizons are shown in Tables 3 and 4 in the online appendix for every month starting in January 2008.
} 
similar albeit less strong case can be made for the real interest rate.

\subsection{Inflation Expectations Curve}

Figure 6 plots inflation expectations obtained from the model for some key horizons, and Figure 8 in the online appendix shows the same information, but with the whole inflation expectations curve plotted for various key dates. In Figure 6 the financial crisis is shown with a vertical line in September 2008, the three Fed programs are shown with yellow shading and the announcement of the formal inflation target is denoted with a dashed-dotted vertical line. The financial crisis causes drastic changes in inflation expectations in the short and medium horizons but not as much in the long horizons. In March 2008 the inflation expectations curve is flat at around $2.4 \%$. In the summer, the short end (e.g., the six-month horizon) edges up to almost 3\%, reflecting the concern about rising energy prices. After the onset of the crisis and the decline of energy prices in September, the short end of the curve takes a big plunge, falling to just above $1 \%$ in December. Throughout the crisis, the long end of the curve remains relatively stable, especially compared with the short end: the 10-year forecast decreases from $2.5 \%$ in July 2008 to $2.4 \%$ in December 2008.

When viewed in a low frequency, the 10-year forecast does not seem to be affected significantly by the financial crisis: in the period September 2008-July 2013, it fluctuates between $2.2 \%$ and $2.4 \%$, with an average of $2.3 \%$, a decline of only 14 basis points. Using the model, I am able to compute the 3-year-to-10-year (starting in year 3, ending in year 10) and 6-yearto-10-year forecasts, which are shown as dashed lines in this figure. These forecasts remain in the pre-crisis levels of around $2.4 \%$. Thus, much of the (already small) decline in the 10-year expectations arises from the expected decline during the first 2 to 5 years. It is also worth mentioning that as the size of the Fed's balance sheet grew rapidly and continuously for much of this period, which could possibly lead to higher inflation, the long-run expectations show no upward trend. My results are in line with Merten's (2011) results, which show that 
trend inflation does not change by much during the crisis.

Turning to the effects of QE1 and QE2, they have similar and large effects on the slope of the inflation expectations curve, and small but opposite effects on the level of the inflation expectations curve. In particular, QE1 increases the six-month expectations from around 1\% in December 2008 to over 1.5\% in August 2010 while mildly reducing longer horizons. QE2, on the other hand, increases the six-month expectations from around 1.5\% in November 2010 to around $2.1 \%$ in June 2011, with milder increases in all other horizons. Figure 8 shows that the effect of QE1 on the curve is a flattening with a slight shift downward in the long end, while QE2 also flattens the curve but shifts it upward. None of these changes, however, bring the inflation expectations curve close to its pre-crisis shape, despite the strong level of mean reversion that is built into the model. One way to see this effect is by computing a counterfactual where the model evolves without shocks starting in December 2008 and then comparing it with the actual evolution. This approach reveals that inflation expectations of all horizons are consistently below the counterfactual, even though they increase relative to the onset of the crisis.

Operation Twist, whose goal was to increase the maturity structure of the Fed balance sheet via purchases of long-term securities and the sale of short-term securities, did not affect inflation expectations in any significant way. Figure 8 shows that the announcement of the formal inflation target in January 2012 seems to shift the level of the inflation expectations curve upward by about 10 basis points and reduce the slope by about 50 basis points. Figure 6 shows, however, that the flattening of the curve is part of a longer-term trend that covers the first half of 2012. We can thus conclude that the announcement of the formal inflation target does not lead to much change in inflation expectations. 


\subsection{Real Interest Rate Curve}

Paralleling the analysis in the previous section, Figure 7 plots some key real interest rates over the period 2008-2013, and Figure 9 in the online appendix shows the full real interest rate curve at various key points in time.

Before turning to the results, I want to explain how I handle the issue I pointed out in Section 2.4. The real interest rate that I compute via (16) in principle inherits the inflation risk premium from nominal yields. Identifying and removing the risk premium requires a financial model. Fortunately, as I explained above, the goal of D'Amico, Kim, and Wei (2010) is precisely to identify the risk premium and liquidity premium components of the TIPS inflation compensation to arrive at inflation expectations. These components are available for the 2-year, 5-year, and 10-year measures. In Figure 7 the dashed lines for these horizons show the real interest rate with the inflation risk premium removed. Although this concern is valid ex ante, the figure shows that for the conclusions I reach below, the risk premium is small enough not to matter.

In January 2008, as the U.S. economy was already slowing down but before the peak of the financial crisis, all real interest rates were positive with a U-shaped real interest curve. As the Fed was reducing the short end of the nominal yield curve throughout 2008, the whole real yield curve also shifts downward significantly. As of December 2008, the real interest rate for horizons up to seven years is negative, with the two-year rate around $-1.4 \%$. Thus, the combination of the financial crisis and the Fed's conventional response leads to a downward shift of the real yield curve, with the short end of the curve remaining higher than the middle.

QE1 reduces the short end of the curve, bringing the six-month rate to around $-1.3 \%$ by the end of the program, at its peak leading to a decline of almost a full percentage point. Despite fluctuations throughout the program, real interest rates of longer maturities remain largely the same after the program ends, although at lower levels relative to those before the financial crisis. QE2 further reduces the short end of the curve by another $0.6 \%$, with the 
longer maturities behaving the same way as they did during QE1. Since the end of QE2, the six-month real interest rates hover just above $-2 \%$. Considering that the average six-month real interest rate in the period $1992-2007$ is $1.5 \%$ with a minimum of $-0.8 \%$ obtained in December 2003, this very low level seems to be highly stimulative.

With Operation Twist, the Fed seems to bring the long end of the real interest rate curve from around $0 \%$ to around $-0.6 \%$. Once again, the average and minimum of this rate in the period $1992-2007$ are $2.8 \%$ and $1.2 \%$, respectively, and the long real rates are also highly stimulative. Since the end of 2012, medium- and long-term real rates have been rising but are still significantly below their pre-crisis levels.

\subsection{Summary}

Here is a summary of the findings in this section:

- The financial crisis and the Fed's conventional response reduced both inflation expectations and real interest rates significantly, with the distinct exception of inflation expectations of long horizons where the decline was very mild. Real interest rates hit unprecedented negative levels for short and medium maturities, indicating that the decline in nominal rates was transmitted to real rates by a less than one-to-one response of inflation expectations.

- Long-run inflation expectations decline by 14 basis points in the 2008-2013 period relative to the pre-crisis average. This small decline can be almost fully attributed to changes in the short-term expectations as the 3-year-to-10-year and 6-year-to-10 year expectations remain constant.

- As a reaction to QE1, and to some extent mean reversion, inflation expectations of short maturities rise by about $0.5 \%$ and by another $0.5 \%$ following QE2. Short-term real rates continue to fall, reaching a low of $-2 \%$ by the end of 2012 . This rate is about $3.5 \%$ below the pre-crisis average. 
- In reaction to QE1, longer-horizon inflation expectations fall by about $0.1 \%$, and in reaction to QE2, they rise by about $0.2 \%$. Despite some fluctuations during the programs, the long-term real rates do not change as a result of these programs.

- Operation Twist does not lead to a change in inflation expectations and reduces the long-term real interest rates by about $0.6 \%$, reaching $-0.8 \%$ in the summer of 2012 . This rate is about $3.6 \%$ below the pre-crisis average.

- The announcement of the formal inflation target does not affect inflation expectations or real interest rates in any significant way.

\section{Conclusions}

Starting in 2008, the Federal Reserve enacted unprecedented policies in response to the biggest decline in economic activity since the Great Depression. The impact of these policies on medium- to long-term inflation are yet to be seen. In this paper I provide a statistically efficient and accurate way of aggregating survey-based inflation expectations into an inflation expectations curve. I also compute a term structure of real interest rates, combining the inflation expectations curve with a nominal yield curve.

The resulting term structure of inflation expectations proves capable of providing superior forecasts relative to some of the popular alternatives that use financial variables, as well as relative to some of the inputs used in the estimation. Thus, moving forward, this approach seems to be a useful tool to gauge inflation expectations at any arbitrary horizon.

I find that neither the financial crisis of 2008 nor the Federal Reserve policies that were put in place during and after it affected the long-run inflation expectations, despite large changes in shorter horizons. The Federal Reserve's unconventional policies, especially QE1 and QE2, had a large effect on the slope of the inflation expectations curve, increasing short-term expectations. As a result, these same policies reduced short-term real rates to 
unprecedented levels. Operation Twist, on the other hand, reduced long-term real rates. All in all, real interest rates of all horizons are about 3.5\% lower than their pre-crisis averages, indicating a massive stimulus to the economy.

From here, a number of further directions are possible. First, a reasonable approach may be to consider non-Gaussian errors or stochastic volatility (or both) in the model. Second, although the model in this paper explicitly excludes financial variables, there may be ways of introducing them without worsening performance. For example, similar to but distinctly different from what Christensen, Lopez, and Rudebusch (2012) do, one could model inflation expectations as I do here and add nominal yields that follow a Nelson-Siegel structure with different factors. Finally, one could introduce information from various online prediction markets. I leave these directions for future work.

\section{References}

[1] Ajello, A., L. Benzoni, and O. Chyruk (2012), "Core and 'Crust': Consumer Prices and the Term Structure of Interest Rates," mimeo, Federal Reserve Bank of Chicago.

[2] Ang, A., G. Bekaert, and M. Wei (2007), "Do Macro Variables, Asset Markets, or Surveys Forecast Inflation Better?" Journal of Monetary Economics, 54(4), 1163-1212.

[3] Aruoba, S.B., F.X. Diebold and C. Scotti (2009), "Real-Time Measurement of Business Conditions," Journal of Business and Economic Statistics, 27(4), 417-427.

[4] Chernov, M., and P. Mueller (2012), "The Term Structure of Inflation Expectations," Journal of Financial Economics, 106(2), 367-394.

[5] Christensen, J.H.E., J.A. Lopez, and G.D. Rudebusch (2010), "Inflation Expectations and Risk Premiums in an Arbitrage-Free Model of Nominal and Real Bond Yields," Journal of Money, Credit and Banking, 42(s1), 143-178. 
[6] Christensen, J.H.E., J.A. Lopez, and G.D. Rudebusch (2012), "Extracting Deflation Probability Forecasts from Treasury Yields," International Journal of Central Banking, $8(4), 21-60$.

[7] D'Amico, S., D.H. Kim, and M. Wei (2010), "Tips from TIPS: The Informational Content of Treasury Inflation-Protected Security Prices," Board of Governors of the Federal Reserve System Finance and Economics Discussion Series, 2010-19.

[8] Diebold, F.X., and C. Li, (2006), "Forecasting the Term Structure of Government Bond Yields," Journal of Econometrics, 130(2), 337-364.

[9] Diebold, F.X., and R.S. Mariano (1995), "Comparing Predictive Accuracy," Journal of Business and Economic Statistics, 13(3), 253-263.

[10] Diebold F.X., and G.D. Rudebusch (2013), Yield Curve Modeling and Forecasting: The Dynamic Nelson-Siegel Approach, Princeton University Press.

[11] Diebold, F.X., G.D. Rudebusch, and S.B. Aruoba (2006), "The Macroeconomy and the Yield Curve: A Dynamic Latent Factor Approach," Journal of Econometrics, 131(1-2), 309-338.

[12] Durbin, J., and S.J. Koopman (2001), Time Series Analysis by State Space Methods, Oxford University Press.

[13] Faust, J., and J.H. Wright (2013), "Forecasting Inflation," in Handbook of Economic Forecasting, vol. 2 pt. A, ed. G. Elliott and A. Timmermann, 2-56, Elsevier.

[14] Gürkaynak, R.S., B. Sack, and J.H. Wright (2007), "The U.S. Treasury Yield Curve: 1961 to the Present," Journal of Monetary Economics, 54(8), 2291-2304.

[15] Gürkaynak, R.S., B. Sack, and J.H. Wright (2010), "The TIPS Yield Curve and Inflation Compensation," American Economic Journal: Macroeconomics, 2(1), 70-92. 
[16] Haubrich, J.G., G. Pennacchi, and P. Ritchken (2012), "Inflation Expectations, Real Rates, and Risk Premia: Evidence from Inflation Swaps," Review of Financial Studies, $25(5), 1588-1629$.

[17] Mertens, E. (2011), "Measuring the Level and Uncertainty of Trend Inflation," Board of Governors of the Federal Reserve System Finance and Economics Discussion Series, 2011-42.

[18] Nelson, C.R., and A.F. Siegel (1987), "Parsimonious Modeling of Yield Curves," Journal of Business, 60(4), 473-489.

[19] Stark, T. (2010), "Realistic Evaluation of Real-Time Forecasts in the Survey of Professional Forecasters," Federal Reserve Bank of Philadelphia Research Rap Special Report. 


\section{Figure 1: Extracted Factors}

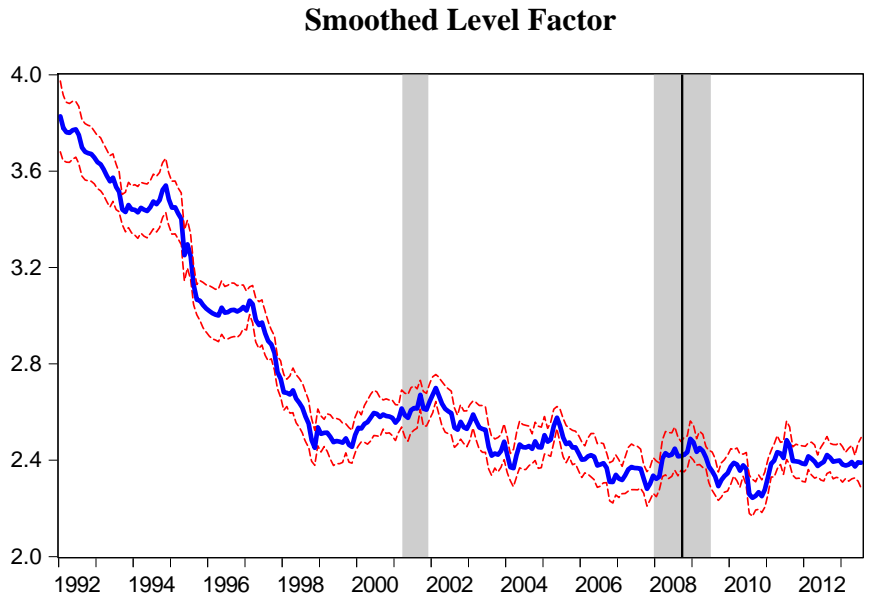

Smoothed Slope Factor

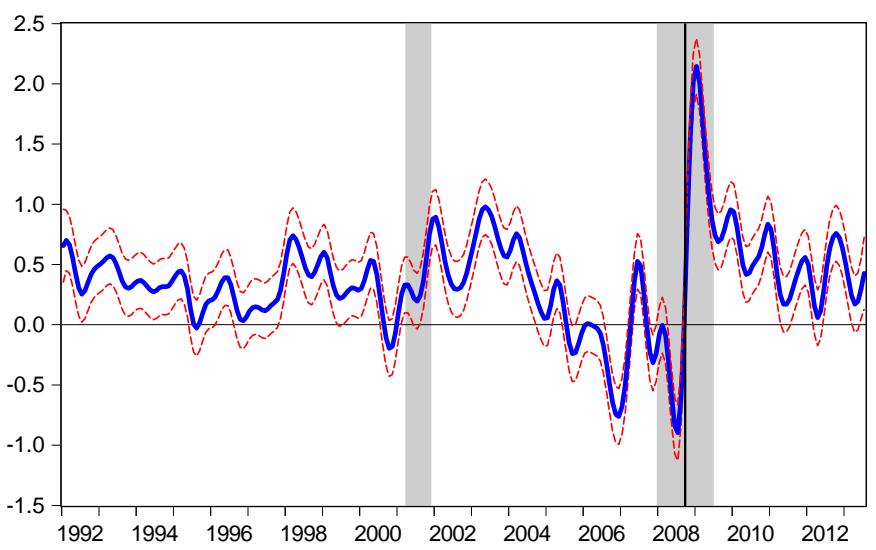

Smoothed Curvature Factor

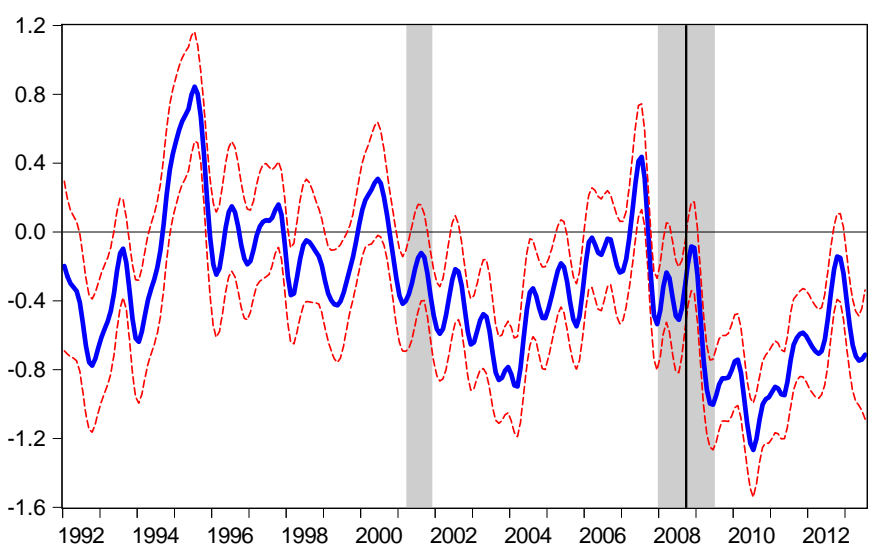

Notes: Gray bars denote NBER recessions. The vertical line denotes September 2008. Blue lines denote the smoothed factors, and red dashed lines show their pointwise $95 \%$ confidence bands. 


\section{Figure 2: Selected Inflation Expectations}
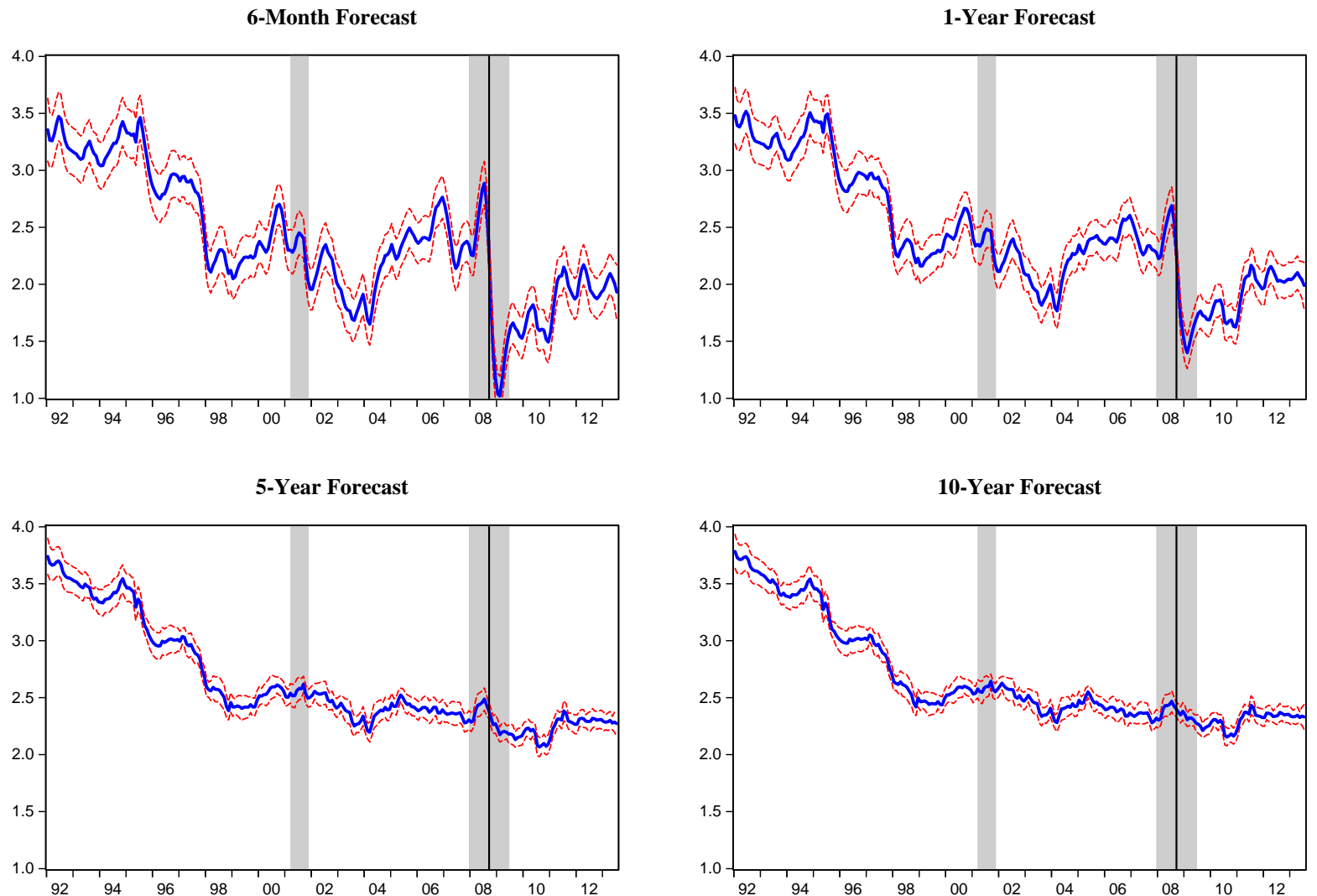

Notes: Gray bars denote NBER recessions. The vertical line denotes September 2008. Blue lines denote the forecasts, and red dashed lines show their pointwise $95 \%$ confidence bands. 
Figure 3: Comparison of One-Year Inflation Expectations with Inputs, Financial Variables, and Actual

(a) Model, Inputs, and Actual

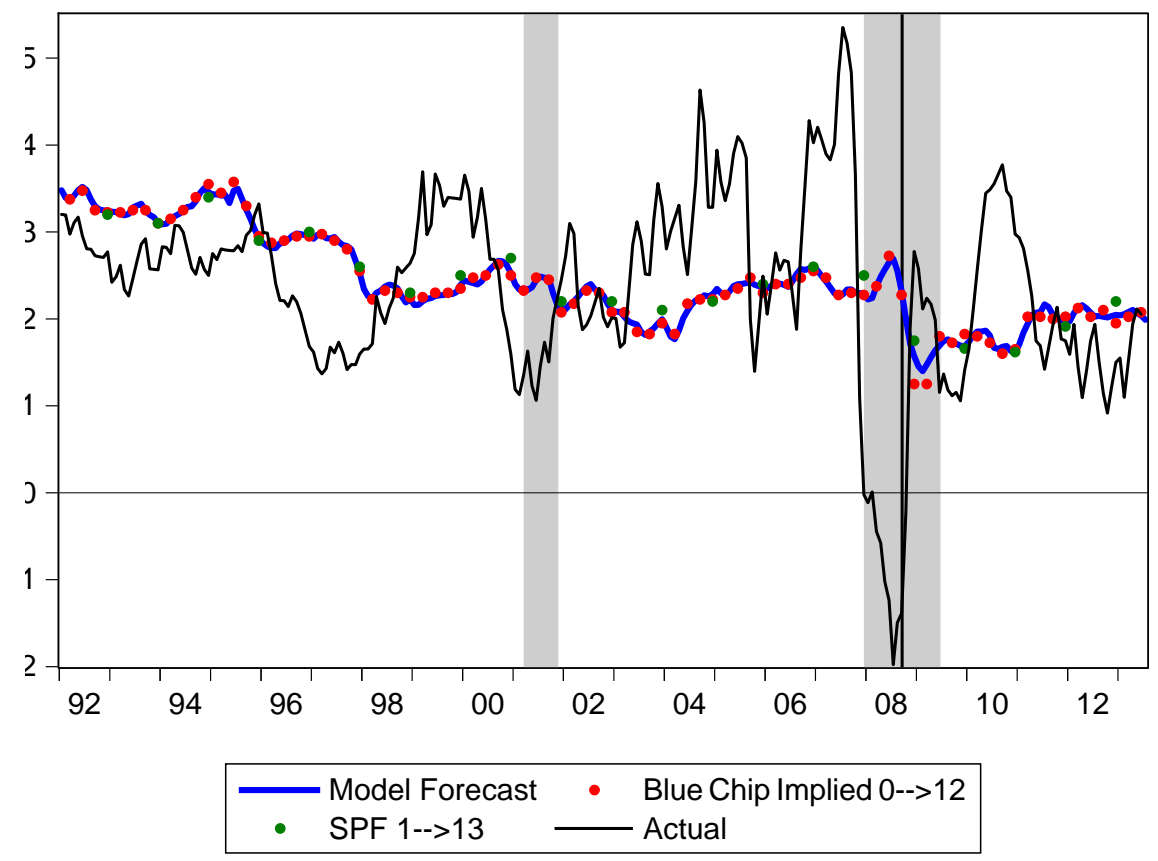

(b) Model, Financial Variables, and Actual

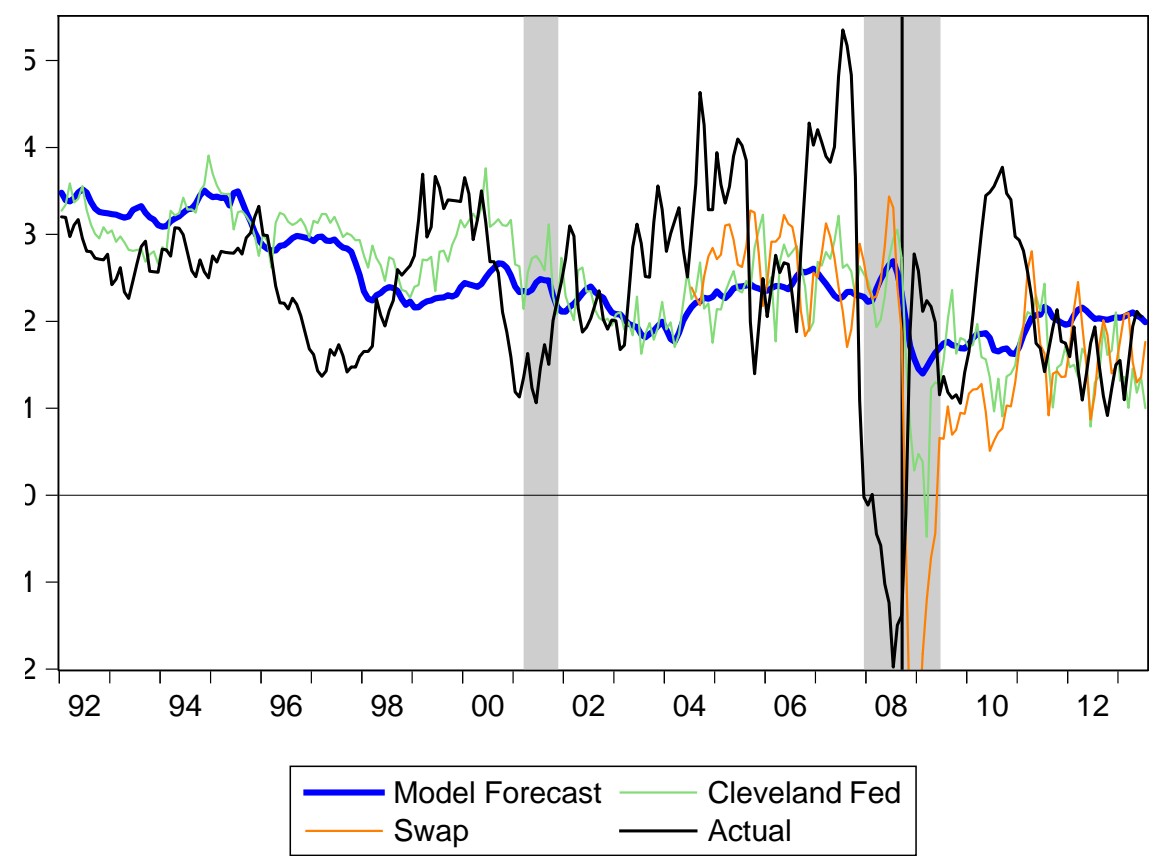

Notes: Gray bars denote NBER recessions. The vertical line denotes September 2008. The swap rate (orange line) falls to $-3.83 \%$ in December 2008 , but the graph is truncated at $-2 \%$. 
Figure 4: Comparison of Five-Year Inflation Expectations with Inputs, Financial Variables, and Actual

(a) Model Forecast, Input, Financial Variables, and Actual

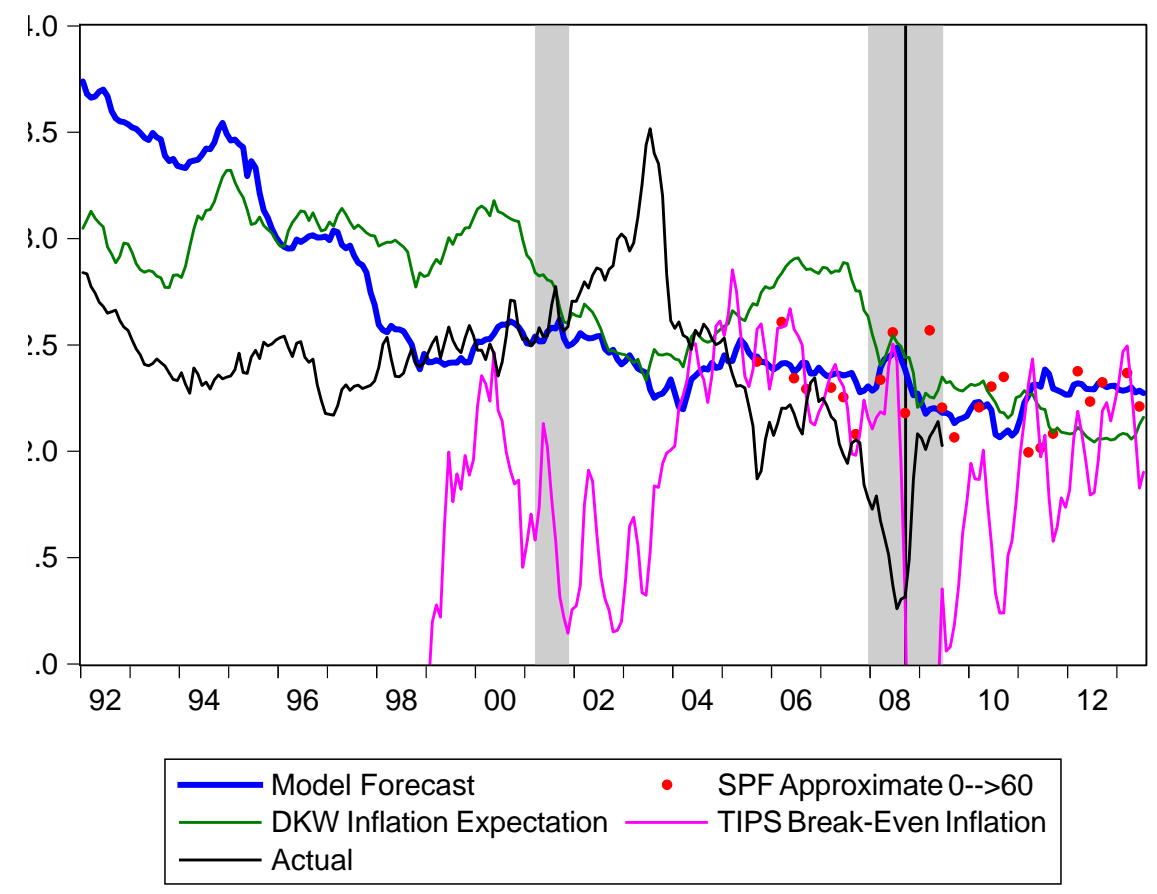

(b) Model Forecast, Financial Variables, and Actual

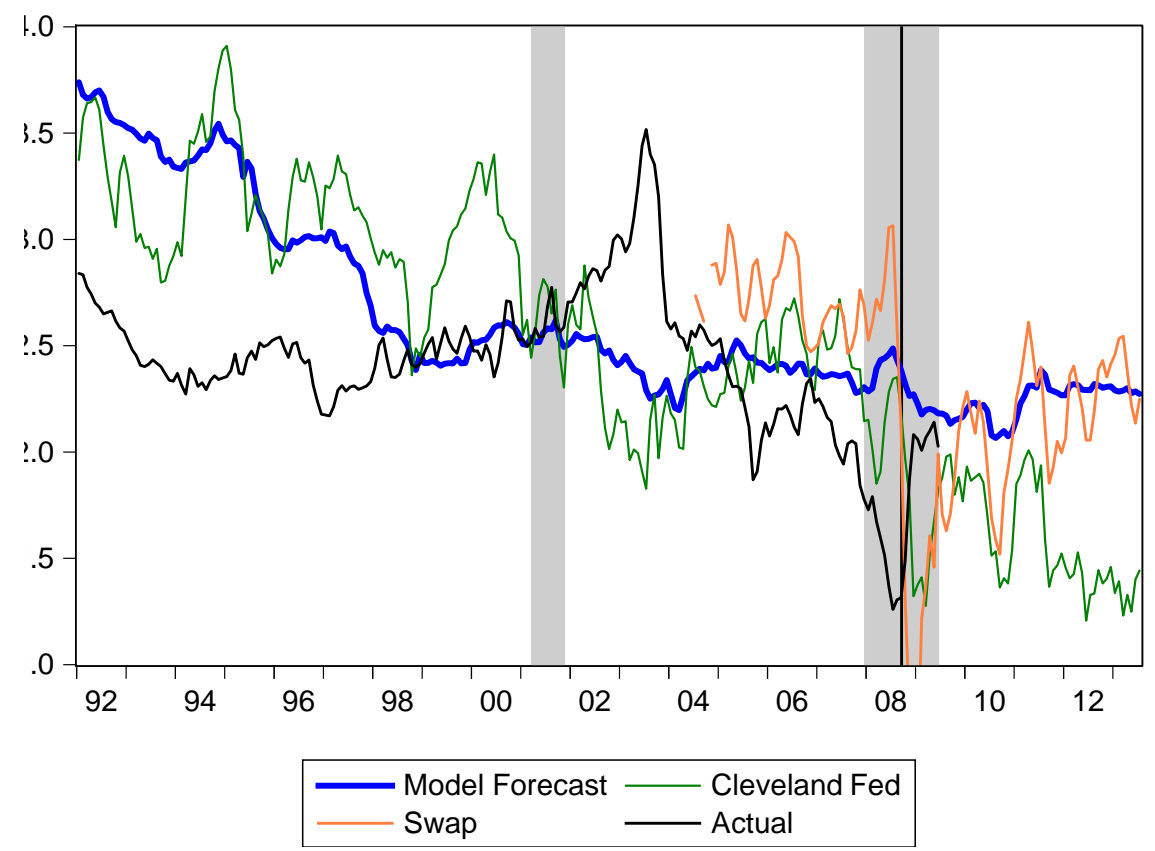

Notes: Gray bars denote NBER recessions. The vertical line denotes September 2008. The TIPS break-even rate (purple line) falls to $-1.33 \%$, and the swap rate (orange line) falls to $-0.19 \%$ in December 2008, but the graph is truncated at $1 \%$. 
Figure 5: Comparison of 10-Year Inflation Expectations with Inputs, Financial Variables, and Actual

(a) Model Forecast, Input, Financial Variables, and Actual

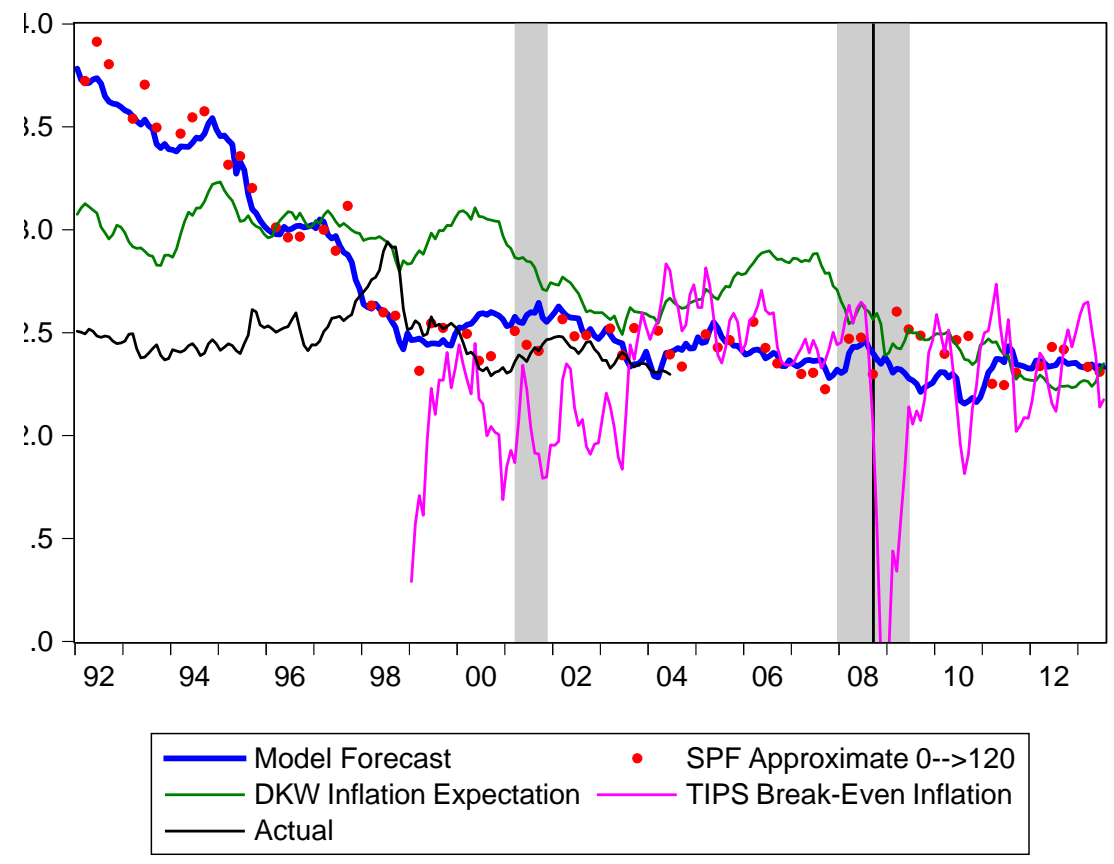

(b) Model Forecast, Financial Variables, and Actual

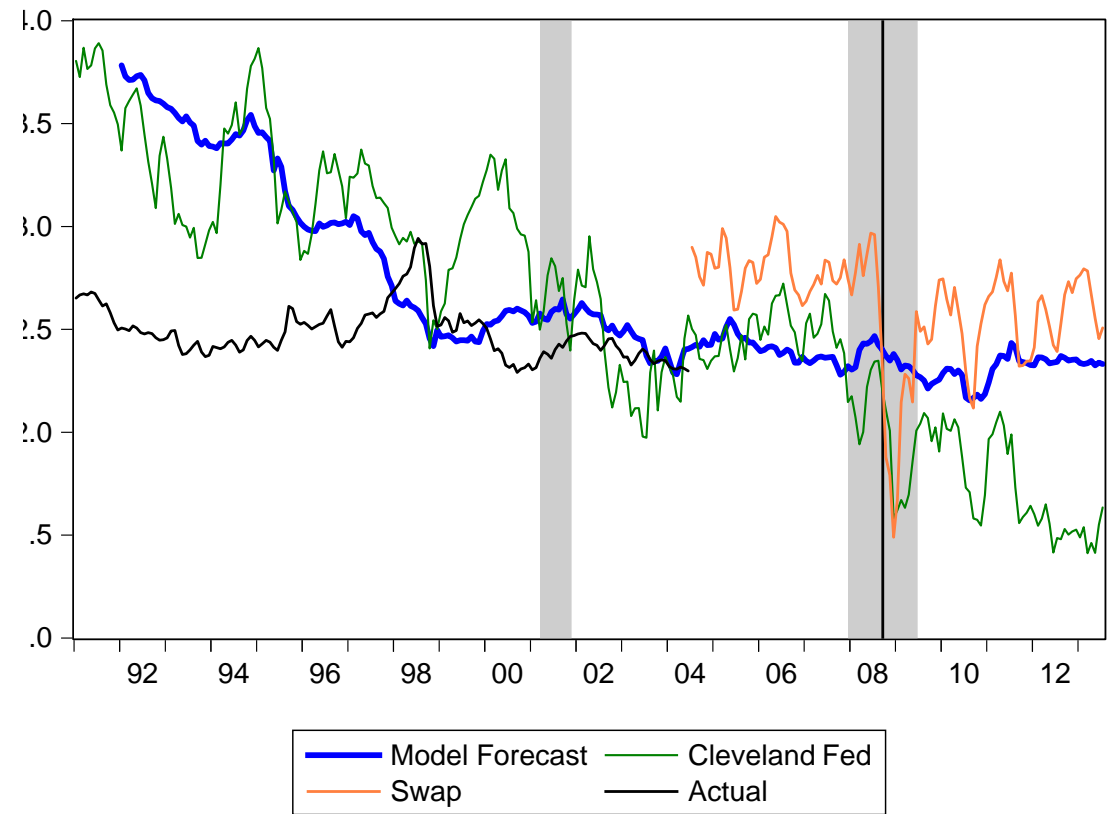

Notes: Gray bars denote NBER recessions. The vertical line denotes September 2008. The TIPS break-even rate (purple line) falls to $0.52 \%$, and the swap rate (orange line) falls to $1.49 \%$ in December 2008, but the graph is truncated at $2 \%$. 
Figure 6: Key Inflation Expectations and Fed Programs

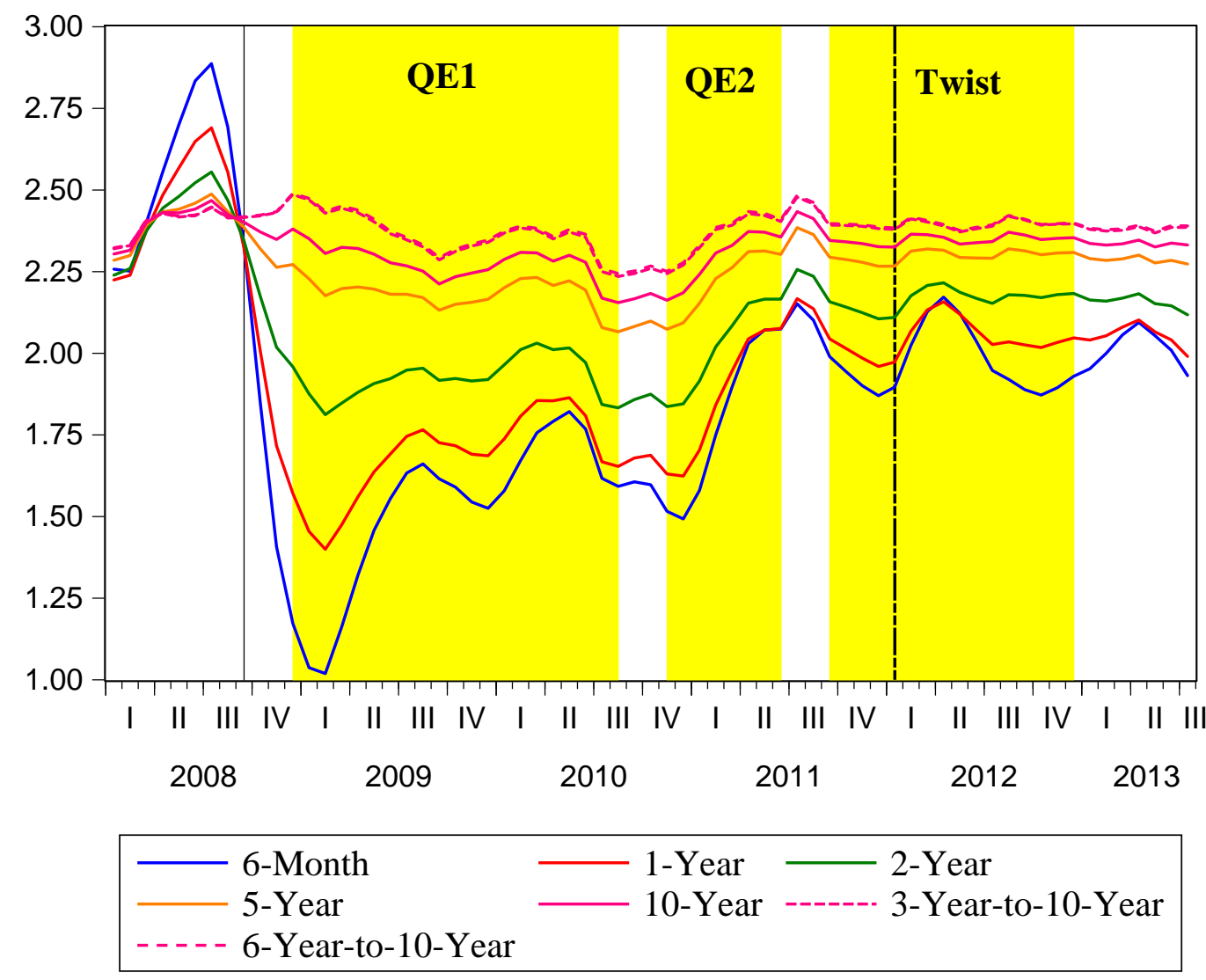

Notes: The solid vertical line denotes September 2008. The yellow shading indicates the months during which the particular Fed program was active. The dashed-dotted vertical line shows January 2012, where the formal inflation target was announced. The two dashed purple lines show the 3-year-to-10-year and 6-year-to-10-year forecasts, which are virtually indistinguishable. 


\section{Figure 7: Key Real Interest Rates and Fed Programs}

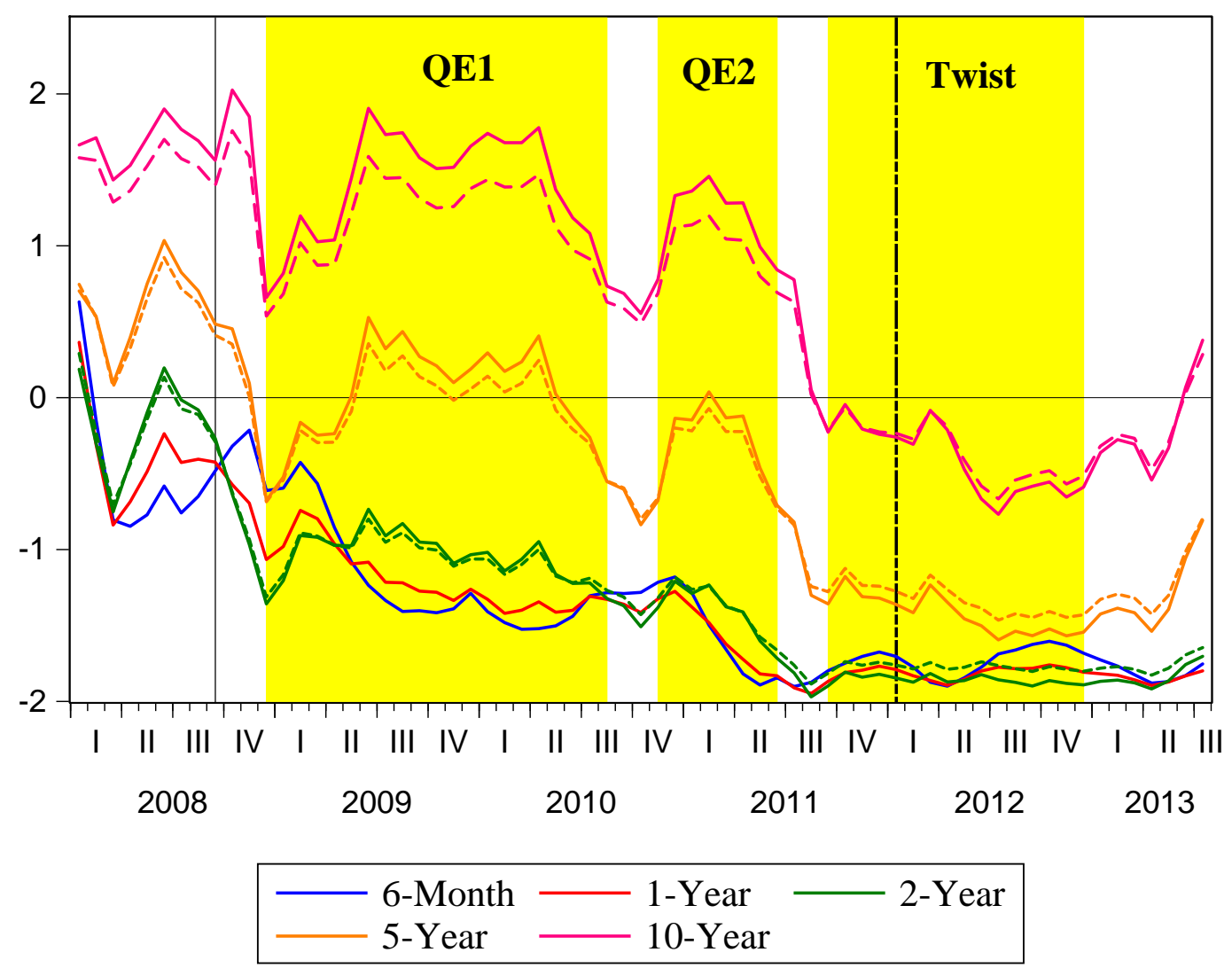

Notes: The solid vertical line denotes September 2008. The yellow shading indicates the months during which the particular Fed program was active. The dashed-dotted vertical line shows January 2012, where the formal inflation target was announced. Dashed lines show the real interest rate for the same horizon as the solid line, cleaned from the inflation risk premium using the measure computed by D'Amico, Kim, and Wei (2010). 
Table 1: Estimation Results

(a) Transition Equation

\begin{tabular}{cc|cc|cc}
\hline \multicolumn{2}{c|}{ Level } & \multicolumn{2}{c}{ Slope } & \multicolumn{2}{c}{ Curvature } \\
\hline$\rho_{11}$ & $\mathbf{1 . 0 0}$ & $\rho_{21}$ & $\mathbf{2 . 2 4}$ & $\rho_{31}$ & $\mathbf{2 . 1 3}$ \\
$\rho_{12}$ & -0.09 & $\rho_{22}$ & $\mathbf{- 1 . 8 8}$ & $\rho_{32}$ & $\mathbf{- 1 . 7 1}$ \\
$\rho_{13}$ & 0.09 & $\rho_{23}$ & $\mathbf{0 . 6 0}$ & $\rho_{33}$ & $\mathbf{0 . 5 5}$ \\
\hline \multicolumn{5}{c}{ Roots of the Characteristic } & Polynomials \\
\hline $0.01 \pm 3.34 i, 1.00$ & $0.99 \pm 0.67 i, 1.18$ & $1.01 \pm 0.81 i, 1.09$ \\
\hline \hline$\mu_{1}$ & $\mathbf{3 . 0 2}$ & $\mu_{2}$ & $\mathbf{0 . 3 6}$ & $\mu_{3}$ & -0.33 \\
\hline \hline$\sigma_{L}^{2}$ & $\mathbf{0 . 0 0 2}$ & $\sigma_{S}^{2}$ & 0.004 & $\sigma_{C}^{2}$ & 0.004 \\
\hline
\end{tabular}

(b) Measurement Equation

\begin{tabular}{|c|c|c|c|c|c|}
\hline \multicolumn{6}{|c|}{$\lambda=0.16$} \\
\hline \multicolumn{2}{|c|}{ SPF Quarterly } & \multicolumn{2}{|c|}{ Blue Chip Short-Run } & \multicolumn{2}{|c|}{ Blue Chip Long-Run } \\
\hline$\sigma_{1}^{2}$ & 0.014 & $\sigma_{16}^{2}$ & 0.061 & $\sigma_{28}^{2}$ & 0.009 \\
\hline$\sigma_{2}^{2}$ & 0.009 & $\sigma_{17}^{10}$ & 0.008 & $\sigma_{29}^{20}$ & 0.008 \\
\hline$\sigma_{3}^{2}$ & 0.006 & $\sigma_{18}^{12}$ & 0.008 & $\sigma_{30}^{29}$ & 0.005 \\
\hline SPF & F Annual & $\sigma_{19}^{2}$ & 0.004 & $\sigma_{31}^{2}$ & 0.003 \\
\hline$\sigma_{4}^{2}$ & 0.009 & $\sigma_{20}^{1}$ & 0.016 & $\sigma_{32}^{2}$ & 0.001 \\
\hline$\sigma_{5}^{2}$ & 0.009 & $\sigma_{21}^{2}$ & 0.010 & $\sigma_{33}^{2}$ & 0.002 \\
\hline$\sigma_{6}^{2}$ & 0.005 & $\sigma_{22}^{2}$ & 0.008 & $\sigma_{34}^{2}$ & 0.003 \\
\hline$\sigma_{7}^{2}$ & 0.016 & $\sigma_{23}^{2}$ & 0.003 & $\sigma_{35}^{2}$ & 0.002 \\
\hline SPF & Five-Year & $\sigma_{24}^{2}$ & 0.006 & \multirow{2}{*}{\multicolumn{2}{|c|}{ Michigan }} \\
\hline$\sigma_{8}^{2}$ & 0.043 & $\sigma_{25}^{2}$ & 0.013 & & \\
\hline$\stackrel{\stackrel{8}{2}}{\sigma_{9}^{2}}$ & 0.031 & $\sigma_{26}^{20}$ & 0.006 & $\sigma_{36}^{2}$ & 0.787 \\
\hline$\sigma_{10}^{2}$ & 0.016 & $\sigma_{27}^{2}$ & 0.004 & $\sigma_{37}^{2}$ & 0.201 \\
\hline$\sigma_{11}^{2}$ & 0.034 & & & & \\
\hline SPF & Ten-Year & & & & \\
\hline$\sigma_{12}^{2}$ & 0.010 & & & & \\
\hline$\sigma_{13}^{2}$ & 0.024 & & & & \\
\hline$\sigma_{14}^{2}$ & 0.016 & & & & \\
\hline$\sigma_{15}^{2}$ & 0.012 & & & & \\
\hline
\end{tabular}

Notes: Boldface indicates significance at the $5 \%$ level. 
Table 2: Forecast Comparison Results

\begin{tabular}{cccc}
\hline Forecast & RMSE - Model & RMSE - Alternative & T \\
\hline Random Walk 1y & $\mathbf{1 . 1 6}$ & 1.64 & 258 \\
Random Walk 2y & $\mathbf{0 . 8 3}$ & 1.43 & 246 \\
Random Walk 5y & $\mathbf{0 . 6 1}$ & 1.13 & 210 \\
Random Walk 10y & 0.62 & 0.69 & 150 \\
\hline \hline Blue Chip 1y & 1.19 & 1.20 & 86 \\
Michigan 1y & 1.16 & 1.50 & 258 \\
SPF 10y & 0.63 & 0.67 & 38 \\
\hline \hline TIPS BE 2y & 0.96 & 1.51 & 102 \\
TIPS BE 5y & $\mathbf{0 . 4 3}$ & 1.02 & 126 \\
TIPS BE 10y & $\mathbf{0 . 1 4}$ & 0.43 & 66 \\
\hline SWAP 1y & 1.52 & 2.00 & 108 \\
SWAP 2y & 0.94 & 1.36 & 95 \\
SWAP 5y & $\mathbf{0 . 4 5}$ & 0.82 & 59 \\
\hline DKW (TIPS sample) 2y & 0.96 & 0.89 & 102 \\
DKW (TIPS sample) 5y & $\mathbf{0 . 4 3}$ & 0.58 & 126 \\
DKW (TIPS sample) 10y & $\mathbf{0 . 1 4}$ & 0.43 & 66 \\
\hline Cleveland 1y & 1.16 & 1.23 & 258 \\
Cleveland 2y & $\mathbf{0 . 8 3}$ & 0.91 & 246 \\
Cleveland 5y & 0.61 & 0.69 & 210 \\
Cleveland 10y & 0.62 & 0.64 & 150 \\
\hline
\end{tabular}

Notes: The first panel shows results for inputs to the estimation. The rest of the panels show results using forecasts obtained from financial variables. Boldface for RMSEs indicates rejection of the null of equal accuracy versus the benchmark forecast at the $5 \%$ level using the Diebold-Mariano (1995) test with squared errors in favor of the model that has the boldface RMSE. 


\section{A Online Appendix}

\section{A.1 Proof of Proposition 1}

Using the definition of inflation in (4), we can write

$$
\begin{aligned}
\frac{s}{s-r} \pi_{t \rightarrow t+s}-\frac{r}{s-r} \pi_{t \rightarrow t+r}= & \frac{s}{s-r} \times 100 \frac{12}{s}\left[\log \left(P_{t+s}\right)-\log \left(P_{t}\right)\right] \\
& -\frac{r}{s-r} \times 100 \frac{12}{r}\left[\log \left(P_{t+r}\right)-\log \left(P_{t}\right)\right] \\
= & 100 \times \frac{12}{s-r}\left\{\left[\log \left(P_{t+s}\right)-\log \left(P_{t}\right)\right]-\left[\log \left(P_{t+r}\right)-\log \left(P_{t}\right)\right]\right\} \\
= & 100 \times \frac{12}{s-r}\left[\log \left(P_{t+s}\right)-\log \left(P_{t+r}\right)\right] \\
= & \pi_{t+r \rightarrow t+s .}
\end{aligned}
$$

\section{A.2 Proof of Proposition 2}

First, using Proposition 1 I can write

$$
\pi_{t+\tau_{1} \rightarrow t+\tau_{2}}=\frac{\tau_{2}}{\tau_{2}-\tau_{1}} \pi_{t}\left(\tau_{2}\right)-\frac{\tau_{1}}{\tau_{2}-\tau_{1}} \pi_{t}\left(\tau_{1}\right)
$$

and then using (2) I get

$$
\begin{aligned}
\pi_{t+\tau_{1} \rightarrow t+\tau_{2}}= & \frac{\tau_{2}}{\tau_{2}-\tau_{1}}\left[L_{t}-\left(\frac{1-e^{-\lambda \tau_{2}}}{\lambda \tau_{2}}\right) S_{t}+\left(\frac{1-e^{-\lambda \tau_{2}}}{\lambda \tau_{2}}-e^{-\lambda \tau_{2}}\right) C_{t}\right] \\
& -\frac{\tau_{1}}{\tau_{2}-\tau_{1}}\left[L_{t}-\left(\frac{1-e^{-\lambda \tau_{1}}}{\lambda \tau_{1}}\right) S_{t}+\left(\frac{1-e^{-\lambda \tau_{1}}}{\lambda \tau_{1}}-e^{-\lambda \tau_{1}}\right) C_{t}\right] \\
= & L_{t}+\frac{e^{-\lambda \tau_{1}}-e^{-\lambda \tau_{2}}}{\lambda\left(\tau_{2}-\tau_{1}\right)}\left(C_{t}-S_{t}\right)+\left(\frac{\tau_{1} e^{-\lambda \tau_{1}}-\tau_{2} e^{-\lambda \tau_{2}}}{\tau_{2}-\tau_{1}}\right) C_{t} .
\end{aligned}
$$




\section{A.3 Measurement Equations}

All the data I use in estimation come from surveys. In some rare cases the forecasters are asked to forecast exactly $\pi_{t}(\tau)$ for some $\tau>0$, and I use these forecasts directly. In many other cases, the question asked of the forecasters does not correspond exactly to a simple $\tau$-month-ahead forecast, so I do some transformations as I explain in detail below. I convert all raw data to annualized percentage points to conform with the notation above. Unless otherwise noted, all data start in 1992. In all cases, the forecasters are asked to forecast the seasonally adjusted CPI inflation rate.

\section{A.3.1 Survey of Professional Forecasters}

The Survey of Professional Forecasters (SPF) is a quarterly survey that has been conducted by the Federal Reserve Bank of Philadelphia since 1990. The forecasters are asked to make forecasts for a number of key macroeconomic indicators several quarters into the future, and in the case of CPI inflation, they are also asked to make 5-year and 10-year forecasts. ${ }^{28} \mathrm{I}$ use the median of these forecasts. The forecasts are normally made around the midpoint of the middle month of a quarter. Since the highest frequency I have is months, and the convention I use is that forecasts are done at the end of a month, I assume instead that these forecasts are made at the end of the middle month of the quarter. The information in Figure 1 in Stark (2010) confirms that, in most cases, the forecasters do not have access to data regarding the previous month when they submit their forecasts; as such, my assumption is innocuous.

SPF Quarterly Forecasts The SPF reports six quarterly forecasts ranging from "minus 1 quarter" to "plus 4 quarters" from the current quarter. The forecasts labeled "4," "5," and "6" are forecasts for two, three, and four quarters after the current quarter. More

\footnotetext{
${ }^{28}$ Federal Reserve Bank of Philadelphia also maintains the Livingston Survey, but since it is based on seasonally unadjusted inflation, I do not use it in this paper.
} 
specifically, the forecasters are asked to forecast the annualized percentage change in the quarterly average of the CPI price level. Using our notation, the " 4 " forecast is

$$
S P F 4=100\left[\left(\frac{P_{t+5}+P_{t+6}+P_{t+7}}{P_{t+2}+P_{t+3}+P_{t+4}}\right)^{4}-1\right],
$$

where the numerator is the average CPI price level in the second quarter following the current one and the denominator is the average CPI price level for the next quarter. Using continuous compounding and geometric averaging, this forecast can be written as $^{29}$

$$
\begin{aligned}
\text { SPF4 } & \approx 400\left\{\log \left[\left(P_{t+5} P_{t+6} P_{t+7}\right)^{1 / 3}\right]-\log \left[\left(P_{t+2} P_{t+3} P_{t+4}\right)^{1 / 3}\right]\right\} \\
& =\frac{400}{3}\left\{\log \left[\left(P_{t+5} P_{t+6} P_{t+7}\right)\right]-\log \left[\left(P_{t+2} P_{t+3} P_{t+4}\right)\right]\right\} \\
& =\frac{400}{3}\left[\log \left(P_{t+5}\right)-\log \left(P_{t+2}\right)+\log \left(P_{t+6}\right)-\log \left(P_{t+3}\right)+\log \left(P_{t+7}\right)-\log \left(P_{t+4}\right)\right] \\
& =\frac{\pi_{t+2 \rightarrow t+5}+\pi_{t+3 \rightarrow t+6}+\pi_{t+4 \rightarrow t+7}}{3},
\end{aligned}
$$

which is the arithmetic average of three quarterly inflation rates. ${ }^{30}$ Using similar derivations for the "5" and " 6 " forecasts, the measurement equations for the quarterly SPF forecasts are

$$
\begin{aligned}
x_{t}^{1} & =\frac{\pi_{t+2 \rightarrow t+5}+\pi_{t+3 \rightarrow t+6}+\pi_{t+4 \rightarrow t+7}}{3}+\varepsilon_{t}^{1} \\
x_{t}^{2} & =\frac{\pi_{t+5 \rightarrow t+8}+\pi_{t+6 \rightarrow t+9}+\pi_{t+7 \rightarrow t+10}}{3}+\varepsilon_{t}^{2} \\
x_{t}^{3} & =\frac{\pi_{t+8 \rightarrow t+11}+\pi_{t+9 \rightarrow t+12}+\pi_{t+10 \rightarrow t+13}}{3}+\varepsilon_{t}^{3} .
\end{aligned}
$$

\footnotetext{
${ }^{29}$ The correlation of actual inflation computed using the exact formula and the approximation I use is 0.9993.

${ }^{30}$ Since the "1," "2," and " 3 " forecasts contain at least some realized inflation rates, I do not use them since I want to focus on pure forecasts.
} 
Once stated as combinations of $\pi_{t+\tau_{1} \rightarrow t+\tau_{2}}$, it is straightforward, though somewhat tedious, to write the full measurement equations for these forecasts using Proposition 2. ${ }^{31}$

SPF "B" Annual Forecast The SPF provides two annual forecasts, one for the current calendar year, and one for the next calendar year. I use the latter, the "B" forecast, since it is purely a forecast into the future. More specifically, in every quarter of the current year the forecasters are asked to forecast the following year's inflation rate. As such, as we progress further into the current year, the forecast horizon becomes shorter. For example, in the first quarter of the current year, the forecast is made at the end of February and forecasts the inflation rate from the end of December of the current year to the end of December next year. As such, it is a forecast of inflation from between 10 months from February and 22 months from February. I treat forecasts in a particular quarter as a separate variable and define $x_{t}^{4}, x_{t}^{5}, x_{t}^{6}$, and $x_{t}^{7}$ as $\pi_{t+10 \rightarrow t+22}, \pi_{t+7 \rightarrow t+19}, \pi_{t+4 \rightarrow t+16}$, and $\pi_{t+1 \rightarrow t+13}$, respectively, plus measurement errors and directly apply Proposition 2 to get the measurement equations. ${ }^{32}$

SPF 5-year and 10-year Forecasts Although much of the SPF contains short- to medium-term forecasts, the forecasters are asked to provide 5-year and 10-year forecasts for inflation as well. In particular, they are asked to forecast 5 and 10 years into the future, starting from the beginning of the current year. Similar to the "B" forecast, I divide the 10-year and the 5-year forecasts into four separate variables, taking into account the different forecast horizons at each quarter. The 10-year forecast has been a part of the SPF since 1991Q4, and the 5-year forecast was added in 2005Q3.

Focusing on the 10-year forecast for now, the forecast released in the first quarter of a year

\footnotetext{
${ }^{31}$ For example, the first measurement equation will be

$$
\begin{aligned}
y_{t}^{1}= & L_{t}+\left[\frac{e^{-2 \lambda}-e^{-5 \lambda}+e^{-3 \lambda}-e^{-6 \lambda}+e^{-4 \lambda}-e^{-7 \lambda}}{3 \lambda}\right]\left(C_{t}-S_{t}\right) \\
& +\left(\frac{2 e^{-2 \lambda}-5 e^{-5 \lambda}+3 e^{-3 \lambda}-6 e^{-6 \lambda}+4 e^{-4 \lambda}-7 e^{-7 \lambda}}{3}\right) C_{t}+\varepsilon_{t}^{1} .
\end{aligned}
$$
}

${ }^{32}$ To be clear, I split the quarterly variable into four variables, each of which is observed only once a year. 
covers the period from the end of December of the previous year until the end of December in 10 years. This forecast is done around February 15. The first quarter is special in that the inflation rate for January is released after February 15, hence after the forecasts are made. Since I assume that the forecasts are done at the end of the month, this forecast will be a combination of an 118-month-ahead forecast and the forecast for inflation in January and February. I assume that the latter is simply equal to the inflation rate in December of the previous year. This means that I can convert the observed SPF to the objects I defined above as

$$
\mathrm{SPF}-10 \mathrm{YR}-\mathrm{Q} 1=\frac{2}{120} \pi_{\text {December }}+\frac{118}{120} \pi_{t \rightarrow t+118}
$$

which is a weighted average of the annualized inflation rate of December of the previous year and the 118-month annualized inflation forecast as of the end of February. ${ }^{33}$ I use Archival Federal Reserve Economic Data (ALFRED) at the Federal Reserve Bank of St. Louis to obtain the exact inflation rate the forecasters would have observed in real time. ${ }^{34}$

Applying a similar logic to the 5-year forecasts, the measurement equations are

$$
\begin{aligned}
x_{t}^{8} & =\pi_{t \rightarrow t+58}+\varepsilon_{t}^{8}=\frac{60}{58}\left(\text { SPF-5YR-Q1 }-\frac{2}{60} \pi_{\text {December }}\right)+\varepsilon_{t}^{8} \\
x_{t}^{9} & =\pi_{t \rightarrow t+55}+\varepsilon_{t}^{9}=\frac{60}{55}\left(\text { SPF-5YR-Q2 }-\frac{5}{60} \pi_{\text {January } \rightarrow \text { March }}\right)+\varepsilon_{t}^{9} \\
x_{t}^{10} & =\pi_{t \rightarrow t+52}+\varepsilon_{t}^{10}=\frac{60}{52}\left(\text { SPF-5YR-Q3 }-\frac{8}{60} \pi_{\text {January } \rightarrow \text { June }}\right)+\varepsilon_{t}^{10} \\
x_{t}^{11} & =\pi_{t \rightarrow t+49}+\varepsilon_{t}^{11}=\frac{60}{49}\left(\text { SPF-5YR-Q } 4-\frac{11}{60} \pi_{\text {January } \rightarrow \text { September }}\right)+\varepsilon_{t}^{11}
\end{aligned}
$$

\footnotetext{
${ }^{33}$ This is obviously an ad hoc assumption. Making alternative assumptions, for example, assuming that the forecasters observe or otherwise have a good idea about the January inflation, does not change the results since its weight in the averaging is only $2 / 120=0.017$.

${ }^{34}$ The data are available at http://alfred.stlouisfed.org/series?seid=CPIAUCSL.
} 
and

$$
\begin{aligned}
& x_{t}^{12}=\pi_{t \rightarrow t+118}+\varepsilon_{t}^{12}=\frac{120}{118}\left(\mathrm{SPF}-10 \mathrm{YR}-\mathrm{Q} 1-\frac{2}{120} \pi_{\text {December }}\right)+\varepsilon_{t}^{12} \\
& x_{t}^{13}=\pi_{t \rightarrow t+115}+\varepsilon_{t}^{13}=\frac{120}{115}\left(\mathrm{SPF}-10 \mathrm{YR}-\mathrm{Q} 2-\frac{5}{120} \pi_{\text {January } \rightarrow \text { March }}\right)+\varepsilon_{t}^{13} \\
& x_{t}^{14}=\pi_{t \rightarrow t+112}+\varepsilon_{t}^{14}=\frac{120}{112}\left(\mathrm{SPF}-10 \mathrm{YR}-\mathrm{Q} 3-\frac{8}{120} \pi_{\text {January } \rightarrow \text { June }}\right)+\varepsilon_{t}^{14} \\
& x_{t}^{15}=\pi_{t \rightarrow t+109}+\varepsilon_{t}^{15}=\frac{120}{109}\left(\mathrm{SPF}-10 \mathrm{YR}-\mathrm{Q} 4-\frac{11}{120} \pi_{\text {January } \rightarrow \text { September }}\right)+\varepsilon_{t}^{15} .
\end{aligned}
$$

The full measurement equations follow from applying Proposition 2.

\section{A.3.2 Blue Chip Forecasts}

I use various forecasts published in Blue Chip Financial Forecasts and Blue Chip Economic Indicators. First, every month the forecasters are asked to make between five to eight shortterm forecasts, up to eight quarters ahead. Dropping any forecast that contains some realized inflation and dropping forecasts further than four quarters, since fewer of these are available because of the unbalanced structure, I use four forecasts. These forecasts are of different horizons depending on the month of the quarter the forecast is made, yielding 12 different observed series. For example, in the first month of the first quarter, forecasts for the Q4 of the previous year, Q1-Q4 of the current year, and Q1-Q4 of the next year are available. Of these, I use the forecasts for Q2-Q4 of the current year and Q1 of the next year. According to the timing conventions adopted in this paper, these are $\pi_{t+2 \rightarrow t+5}, \pi_{t+5 \rightarrow t+8}, \pi_{t+8 \rightarrow t+11}$ and $\pi_{t+11 \rightarrow t+14}$. Similarly, in the second month of a quarter, I observe $\pi_{t+1 \rightarrow t+4}, \pi_{t+4 \rightarrow t+7}$, $\pi_{t+7 \rightarrow t+10}$, and $\pi_{t+10 \rightarrow t+13}$ and in the third month of a quarter, I observe $\pi_{t \rightarrow t+3}, \pi_{t+3 \rightarrow t+6}$, $\pi_{t+6 \rightarrow t+9}$ and $\pi_{t+9 \rightarrow t+12}$. The variables, labeled $x_{t}^{i}$ for $i=16,18, \ldots, 27$, have measurement equations directly obtained from Proposition 2 with measurement errors $\varepsilon_{t}^{i}$.

Second, every three months, in the March and October issues of the Blue Chip Economic Indicators and the June and December issues of the Blue Chip Financial Forecasts, the forecasters are asked about their long-term forecasts, up to the next 11 years. More specifically, 
they are asked for forecasts of inflation during five calendar years (typically the five years starting from the next one, but sometimes starting from the one after that), the five-yearly forecast covering the same calendar years, and the five years immediately following those. It is straightforward to combine the latter five-yearly forecasts to obtain a 10-year forecast. Expressing these forecasts using the notation so far, these are $\pi_{t+13 \rightarrow t+73}, \pi_{t+13 \rightarrow t+133}$, $\pi_{t+15 \rightarrow t+75}, \pi_{t+15 \rightarrow t+135}, \pi_{t+19 \rightarrow t+79}, \pi_{t+19 \rightarrow t+139}, \pi_{t+22 \rightarrow t+82}$, and $\pi_{t+22 \rightarrow t+142}$, and labeled $x_{t}^{i}$ for $i=28,29, \ldots, 35$. The measurement equations are directly obtained from Proposition 2 with measurement errors $\varepsilon_{t}^{i}$.

\section{A.3.3 University of Michigan Inflation Expectation}

As a part of the Reuters/University of Michigan Survey of Consumers, respondents are asked to forecast inflation in the next 12 months. The median values of these responses are obtained from Federal Reserve Economic Data (FRED) hosted by the Federal Reserve Bank of St. Louis. This fits exactly in the notation above as

$$
x_{t}^{36}=\pi_{t \rightarrow t+12}+\varepsilon_{t}^{36},
$$

and the measurement equation directly follows from (2).

In addition to this short-term forecast, the Michigan survey has another question that asks for "inflation expectations over the next 5-10 years." I interpret this to mean the average of inflation expectations over horizons starting from 60 months until 120 months (5-, 6-, 7-, 8-, 9-, and 10-year inflation expectations). ${ }^{35}$ Thus, the measurement equation is

$$
x_{t}^{37}=\frac{1}{6}\left(\pi_{t \rightarrow t+60}+\pi_{t \rightarrow t+72}+\pi_{t \rightarrow t+84}+\pi_{t \rightarrow t+96}+\pi_{t \rightarrow t+108}+\pi_{t \rightarrow t+120}\right)+\varepsilon_{t}^{37},
$$

to which the results from Proposition 2 are applied.

\footnotetext{
${ }^{35}$ Unfortunately the documentation of the survey is not very clear about the exact meaning of "over the next 5-10 years."
} 
Figure 8: Inflation Expectations Curves

Before and During the Financial Crisis and QE1

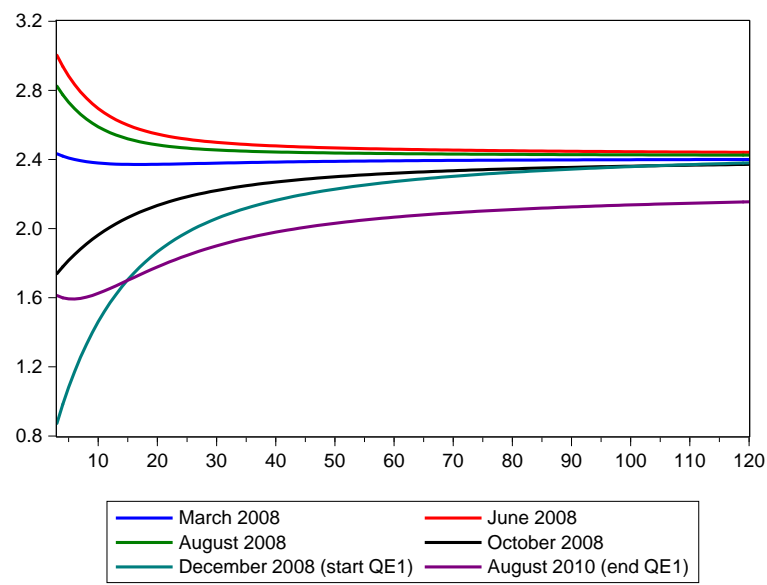

Before and After Operation Twist

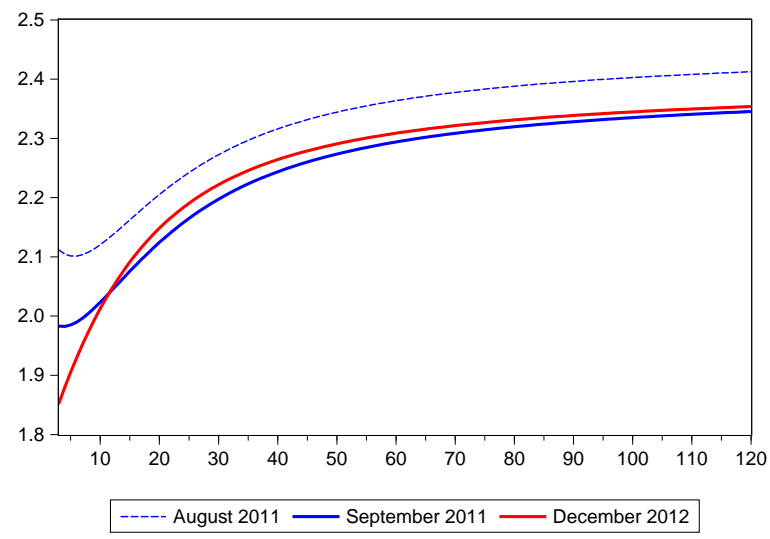

Before and After QE2

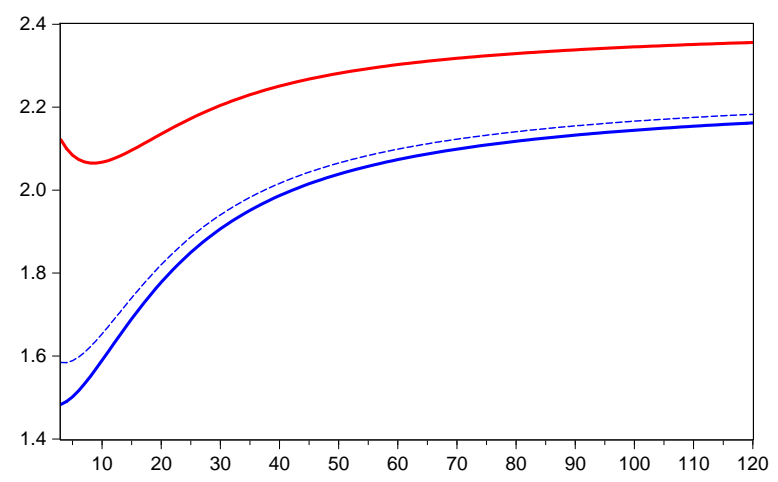

----- October 2010 — November 2010 (start QE2) — June 2011 (end QE2)

Before and After Announcement of Formal Inflation Target

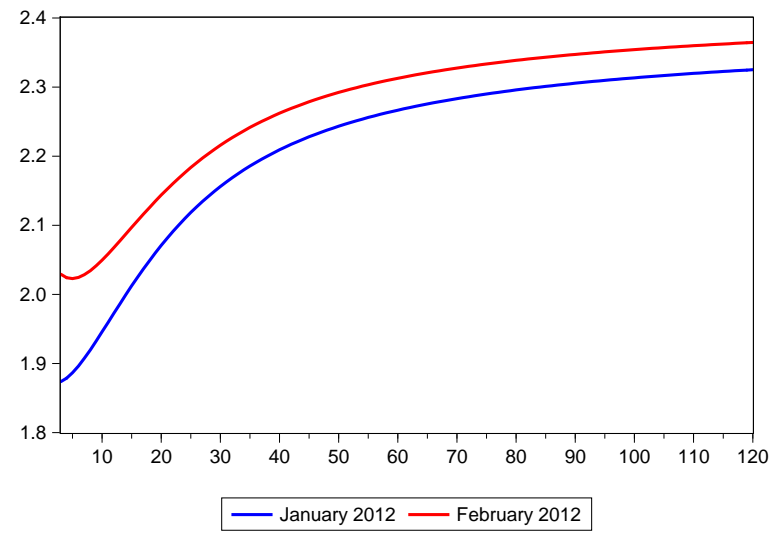

Notes: The $x$-axis is in months, and each figure starts with the 3-month forecast and goes up to the 10-year forecast. 


\section{Figure 9: Real Interest Rate Curves}

Before and During the Financial Crisis and QE1

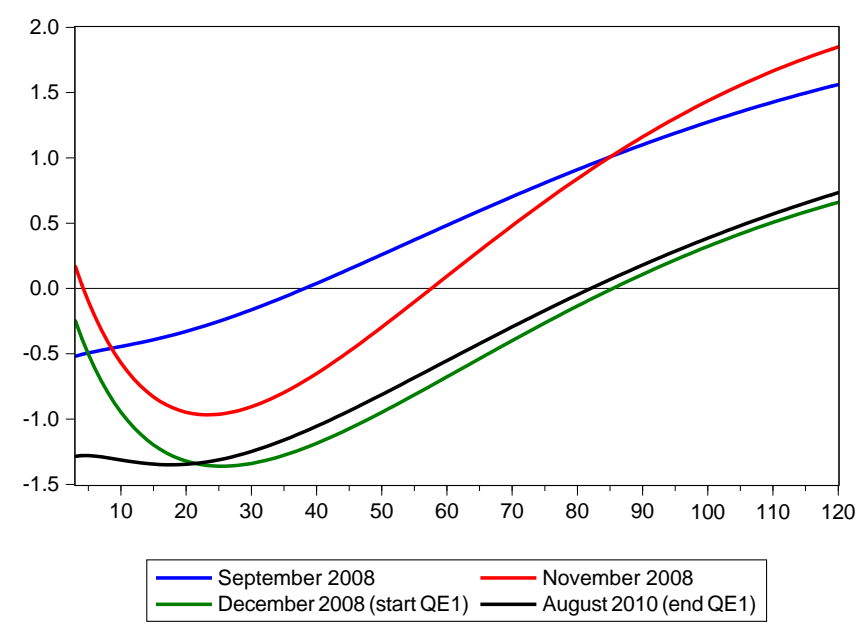

Before and After QE2

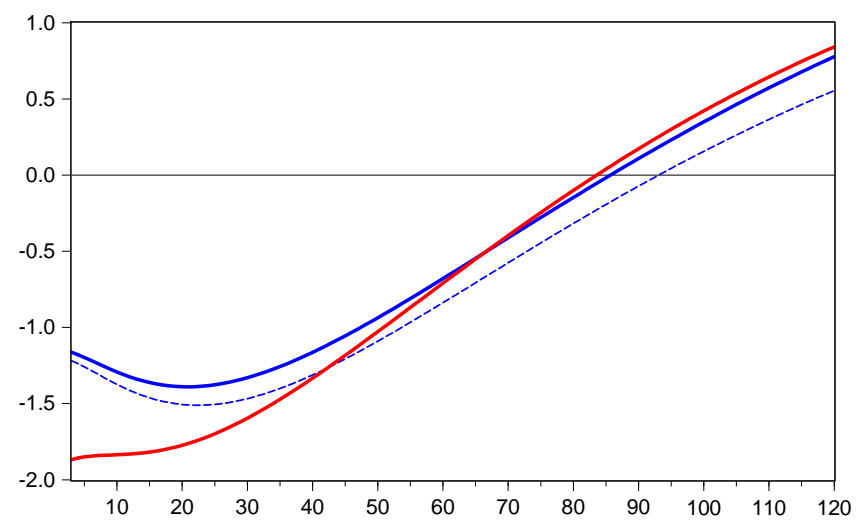

----- October 2010 — November 2010 (start QE2) —— June 2011 (end QE2)

Before and After Operation Twist

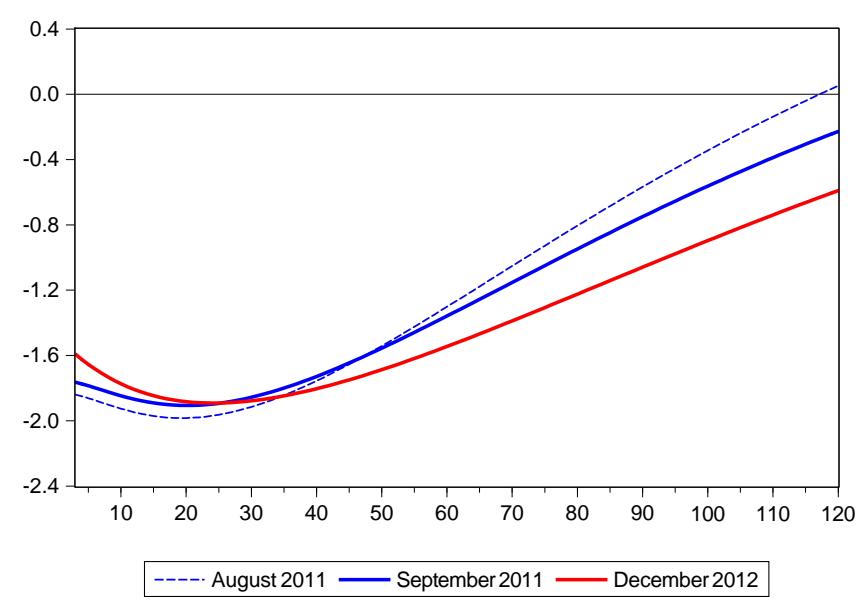

Notes: The $x$-axis is in months, and each figure starts with the 3-month forecast and goes up to the 10-year forecast. 
Table 3: Inflation Expectations - 2008-2013

\begin{tabular}{|c|c|c|c|c|c|c|}
\hline & 1-year & 2-year & 5-year & 10-year & 3-year-to-10-year & 6-year-to-10-year \\
\hline 2008M01 & 2.22 & 2.24 & 2.28 & 2.30 & 2.32 & 2.32 \\
\hline 2008M02 & 2.24 & 2.26 & 2.30 & 2.32 & 2.33 & 2.33 \\
\hline 2008M03 & 2.37 & 2.37 & 2.39 & 2.40 & 2.41 & 2.41 \\
\hline 2008M04 & 2.48 & 2.44 & 2.43 & 2.43 & 2.43 & 2.43 \\
\hline $2008 \mathrm{M} 05$ & 2.57 & 2.48 & 2.44 & 2.43 & 2.42 & 2.42 \\
\hline 2008M06 & 2.65 & 2.52 & 2.46 & 2.44 & 2.42 & 2.42 \\
\hline 2008M07 & 2.69 & 2.56 & 2.49 & 2.47 & 2.45 & 2.45 \\
\hline 2008M08 & 2.56 & 2.47 & 2.43 & 2.43 & 2.41 & 2.42 \\
\hline 2008M09 & 2.32 & 2.34 & 2.39 & 2.40 & 2.42 & 2.42 \\
\hline $2008 \mathrm{M} 10$ & 2.01 & 2.17 & 2.32 & 2.37 & 2.42 & 2.42 \\
\hline $2008 \mathrm{M} 11$ & 1.72 & 2.02 & 2.26 & 2.35 & 2.43 & 2.43 \\
\hline 2008M12 & 1.57 & 1.96 & 2.27 & 2.38 & 2.49 & 2.49 \\
\hline 2009M01 & 1.45 & 1.88 & 2.23 & 2.35 & 2.47 & 2.47 \\
\hline 2009M02 & 1.40 & 1.81 & 2.18 & 2.31 & 2.43 & 2.43 \\
\hline 2009M03 & 1.47 & 1.85 & 2.20 & 2.32 & 2.44 & 2.45 \\
\hline 2009M04 & 1.56 & 1.88 & 2.20 & 2.32 & 2.43 & 2.44 \\
\hline 2009M05 & 1.64 & 1.91 & 2.20 & 2.30 & 2.40 & 2.41 \\
\hline 2009M06 & 1.69 & 1.92 & 2.18 & 2.28 & 2.37 & 2.37 \\
\hline 2009M07 & 1.75 & 1.95 & 2.18 & 2.27 & 2.35 & 2.35 \\
\hline 2009M08 & 1.77 & 1.95 & 2.17 & 2.25 & 2.33 & 2.33 \\
\hline 2009M09 & 1.73 & 1.92 & 2.13 & 2.21 & 2.29 & 2.29 \\
\hline 2009M10 & 1.72 & 1.92 & 2.15 & 2.23 & 2.31 & 2.32 \\
\hline 2009M11 & 1.69 & 1.91 & 2.16 & 2.25 & 2.33 & 2.33 \\
\hline 2009M12 & 1.69 & 1.92 & 2.17 & 2.26 & 2.34 & 2.35 \\
\hline 2010M01 & 1.74 & 1.96 & 2.20 & 2.29 & 2.37 & 2.37 \\
\hline 2010M02 & 1.81 & 2.01 & 2.23 & 2.31 & 2.38 & 2.39 \\
\hline 2010M03 & 1.85 & 2.03 & 2.23 & 2.31 & 2.38 & 2.38 \\
\hline 2010M04 & 1.85 & 2.01 & 2.21 & 2.28 & 2.35 & 2.36 \\
\hline 2010M05 & 1.86 & 2.02 & 2.22 & 2.30 & 2.37 & 2.38 \\
\hline 2010M06 & 1.81 & 1.97 & 2.19 & 2.28 & 2.36 & 2.36 \\
\hline 2010M07 & 1.67 & 1.84 & 2.08 & 2.17 & 2.25 & 2.26 \\
\hline 2010M08 & 1.65 & 1.83 & 2.07 & 2.15 & 2.24 & 2.24 \\
\hline 2010M09 & 1.68 & 1.86 & 2.08 & 2.17 & 2.24 & 2.25 \\
\hline 2010M10 & 1.69 & 1.87 & 2.10 & 2.18 & 2.26 & 2.27 \\
\hline 2010M11 & 1.63 & 1.84 & 2.07 & 2.16 & 2.24 & 2.25 \\
\hline 2010M12 & 1.62 & 1.85 & 2.09 & 2.19 & 2.27 & 2.28 \\
\hline 2011M01 & 1.70 & 1.91 & 2.15 & 2.24 & 2.32 & 2.33 \\
\hline 2011M02 & 1.84 & 2.02 & 2.23 & 2.31 & 2.38 & 2.39 \\
\hline 2011M03 & 1.95 & 2.08 & 2.26 & 2.33 & 2.39 & 2.40 \\
\hline 2011M04 & 2.04 & 2.15 & 2.31 & 2.37 & 2.43 & 2.43 \\
\hline
\end{tabular}


Table 3 - Inflation Expectations, 2008-2013 (continued)

\begin{tabular}{lcccccc}
\hline & 1-year & 2-year & 5-year & 10-year & 3-year-to-10-year & 6-year-to-10-year \\
\hline 2011M05 & 2.07 & 2.17 & 2.31 & 2.37 & 2.42 & 2.43 \\
2011M06 & 2.08 & 2.17 & 2.30 & 2.36 & 2.40 & 2.41 \\
2011M07 & 2.17 & 2.26 & 2.38 & 2.43 & 2.48 & 2.48 \\
2011M08 & 2.14 & 2.24 & 2.36 & 2.41 & 2.46 & 2.46 \\
2011M09 & 2.04 & 2.16 & 2.29 & 2.35 & 2.39 & 2.40 \\
2011M10 & 2.01 & 2.14 & 2.29 & 2.34 & 2.39 & 2.40 \\
2011M11 & 1.99 & 2.12 & 2.28 & 2.34 & 2.39 & 2.39 \\
2011M12 & 1.96 & 2.11 & 2.27 & 2.33 & 2.38 & 2.39 \\
2012M01 & 1.97 & 2.11 & 2.27 & 2.33 & 2.38 & 2.38 \\
2012M02 & 2.07 & 2.18 & 2.31 & 2.36 & 2.41 & 2.41 \\
2012M03 & 2.13 & 2.21 & 2.32 & 2.36 & 2.40 & 2.39 \\
2012M04 & 2.16 & 2.22 & 2.32 & 2.35 & 2.39 & 2.38 \\
2012M05 & 2.12 & 2.19 & 2.29 & 2.33 & 2.37 & 2.39 \\
2012M06 & 2.07 & 2.17 & 2.29 & 2.34 & 2.38 & 2.42 \\
2012M07 & 2.03 & 2.15 & 2.29 & 2.34 & 2.39 & 2.41 \\
2012M08 & 2.03 & 2.18 & 2.32 & 2.37 & 2.42 & 2.39 \\
2012M09 & 2.03 & 2.18 & 2.31 & 2.36 & 2.41 & 2.40 \\
2012M10 & 2.02 & 2.17 & 2.30 & 2.35 & 2.39 & 2.40 \\
2012M11 & 2.03 & 2.18 & 2.31 & 2.35 & 2.39 & 2.38 \\
2012M12 & 2.05 & 2.18 & 2.31 & 2.35 & 2.40 & 2.38 \\
2013M01 & 2.04 & 2.16 & 2.29 & 2.34 & 2.38 & 2.39 \\
2013M02 & 2.05 & 2.16 & 2.28 & 2.33 & 2.37 & \\
2013M03 & 2.08 & 2.17 & 2.29 & 2.34 & 2.38 & 2.39 \\
2013M04 & 2.10 & 2.18 & 2.30 & 2.35 & 2.39 & \\
2013M05 & 2.07 & 2.15 & 2.28 & 2.33 & 2.39 & \\
2013M06 & 2.04 & 2.15 & 2.28 & 2.34 & & \\
2013M07 & 1.99 & 2.12 & 2.27 & 2.33 & & \\
\hline & & & & & & \\
\end{tabular}


Table 4: Real Interest Rates, 2008-2013

\begin{tabular}{|c|c|c|c|c|c|}
\hline & 6-month & 1-year & 2-year & 5-year & 10-year \\
\hline 2008M01 & 0.63 & 0.36 & 0.19 & 0.70 & 1.66 \\
\hline 2008M02 & -0.15 & -0.31 & -0.30 & 0.54 & 1.71 \\
\hline 2008M03 & -0.81 & -0.84 & -0.75 & 0.09 & 1.43 \\
\hline 2008M04 & -0.85 & -0.69 & -0.42 & 0.40 & 1.53 \\
\hline 2008M05 & -0.77 & -0.49 & -0.10 & 0.75 & 1.71 \\
\hline 2008M06 & -0.58 & -0.24 & 0.20 & 1.03 & 1.90 \\
\hline 2008M07 & -0.76 & -0.43 & -0.02 & 0.83 & 1.77 \\
\hline 2008M08 & -0.65 & -0.41 & -0.08 & 0.70 & 1.69 \\
\hline 2008M09 & -0.48 & -0.42 & -0.27 & 0.48 & 1.56 \\
\hline 2008M10 & -0.32 & -0.57 & -0.64 & 0.45 & 2.03 \\
\hline 2008M11 & -0.21 & -0.69 & -0.97 & 0.09 & 1.85 \\
\hline 2008M12 & -0.61 & -1.07 & -1.36 & -0.68 & 0.66 \\
\hline 2009M01 & -0.60 & -0.98 & -1.21 & -0.52 & 0.82 \\
\hline 2009M02 & -0.43 & -0.74 & -0.91 & -0.16 & 1.20 \\
\hline 2009M03 & -0.57 & -0.80 & -0.92 & -0.25 & 1.03 \\
\hline 2009M04 & -0.86 & -0.96 & -0.97 & -0.24 & 1.04 \\
\hline 2009M05 & -1.08 & -1.10 & -0.98 & 0.01 & 1.45 \\
\hline 2009M06 & -1.24 & -1.08 & -0.73 & 0.53 & 1.90 \\
\hline 2009M07 & -1.34 & -1.22 & -0.91 & 0.32 & 1.73 \\
\hline 2009M08 & -1.41 & -1.22 & -0.83 & 0.43 & 1.74 \\
\hline 2009M09 & -1.40 & -1.27 & -0.95 & 0.27 & 1.58 \\
\hline 2009M10 & -1.42 & -1.28 & -0.96 & 0.21 & 1.51 \\
\hline 2009M11 & -1.39 & -1.34 & -1.09 & 0.10 & 1.52 \\
\hline 2009M12 & -1.29 & -1.26 & -1.03 & 0.19 & 1.66 \\
\hline 2010M01 & -1.41 & -1.33 & -1.02 & 0.30 & 1.74 \\
\hline 2010M02 & -1.48 & -1.42 & -1.14 & 0.17 & 1.68 \\
\hline 2010M03 & -1.53 & -1.40 & -1.06 & 0.24 & 1.68 \\
\hline 2010M04 & -1.52 & -1.35 & -0.95 & 0.41 & 1.78 \\
\hline 2010M05 & -1.50 & -1.41 & -1.16 & 0.02 & 1.37 \\
\hline 2010M06 & -1.44 & -1.40 & -1.22 & -0.13 & 1.18 \\
\hline 2010M07 & -1.31 & -1.31 & -1.22 & -0.26 & 1.08 \\
\hline 2010M08 & -1.28 & -1.33 & -1.32 & -0.55 & 0.73 \\
\hline 2010M09 & -1.29 & -1.36 & -1.37 & -0.60 & 0.69 \\
\hline 2010M10 & -1.28 & -1.41 & -1.51 & -0.84 & 0.55 \\
\hline 2010M11 & -1.22 & -1.32 & -1.38 & -0.68 & 0.78 \\
\hline 2010M12 & -1.18 & -1.28 & -1.21 & -0.14 & 1.33 \\
\hline 2011M01 & -1.28 & -1.38 & -1.29 & -0.15 & 1.36 \\
\hline 2011M02 & -1.50 & -1.48 & -1.23 & 0.04 & 1.46 \\
\hline 2011M03 & -1.66 & -1.62 & -1.38 & -0.13 & 1.28 \\
\hline 2011M04 & -1.82 & -1.72 & -1.41 & -0.12 & 1.28 \\
\hline
\end{tabular}

Continued on next page 
Table 4 - Real Interest Rates - 2008-2013 (continued)

\begin{tabular}{|c|c|c|c|c|c|}
\hline & 6-month & 1-year & 2-year & 5-year & 10-year \\
\hline 2011M05 & -1.89 & -1.82 & -1.60 & -0.46 & 0.99 \\
\hline 2011M06 & -1.84 & -1.83 & -1.72 & -0.71 & 0.84 \\
\hline 2011M07 & -1.90 & -1.91 & -1.81 & -0.82 & 0.78 \\
\hline 2011M08 & -1.87 & -1.95 & -1.97 & -1.30 & 0.05 \\
\hline 2011M09 & -1.80 & -1.87 & -1.90 & -1.36 & -0.23 \\
\hline 2011M10 & -1.75 & -1.81 & -1.81 & -1.18 & -0.05 \\
\hline 2011M11 & -1.70 & -1.80 & -1.84 & -1.31 & -0.21 \\
\hline 2011M12 & -1.68 & -1.77 & -1.82 & -1.32 & -0.24 \\
\hline 2012M01 & -1.70 & -1.79 & -1.85 & -1.36 & -0.26 \\
\hline 2012M02 & -1.77 & -1.83 & -1.87 & -1.42 & -0.31 \\
\hline 2012M03 & -1.87 & -1.86 & -1.82 & -1.23 & -0.08 \\
\hline 2012M04 & -1.90 & -1.89 & -1.87 & -1.35 & -0.21 \\
\hline 2012M05 & -1.85 & -1.85 & -1.86 & -1.46 & -0.47 \\
\hline 2012M06 & -1.77 & -1.80 & -1.82 & -1.50 & -0.67 \\
\hline 2012M07 & -1.69 & -1.77 & -1.86 & -1.60 & -0.77 \\
\hline 2012M08 & -1.66 & -1.78 & -1.88 & -1.54 & -0.62 \\
\hline 2012M09 & -1.63 & -1.78 & -1.90 & -1.57 & -0.58 \\
\hline 2012M10 & -1.60 & -1.76 & -1.86 & -1.52 & -0.56 \\
\hline 2012M11 & -1.63 & -1.78 & -1.88 & -1.57 & -0.66 \\
\hline 2012M12 & -1.68 & -1.81 & -1.89 & -1.54 & -0.59 \\
\hline 2013M01 & -1.73 & -1.82 & -1.87 & -1.42 & -0.36 \\
\hline 2013M02 & -1.77 & -1.83 & -1.86 & -1.39 & -0.28 \\
\hline 2013M03 & -1.82 & -1.86 & -1.88 & -1.42 & -0.31 \\
\hline 2013M04 & -1.88 & -1.90 & -1.92 & -1.54 & -0.54 \\
\hline 2013M05 & -1.87 & -1.87 & -1.86 & -1.39 & -0.33 \\
\hline 2013M06 & -1.83 & -1.83 & -1.76 & -1.06 & 0.07 \\
\hline 2013M07 & -1.75 & -1.80 & -1.70 & -0.81 & 0.38 \\
\hline
\end{tabular}

